\title{
Prediction of Inhomogeneous Distribution of Microalloy Precipitates in Continuous-Cast High-Strength, Low-Alloy Steel Slab
}

\author{
SUPARNA ROY, SUDIPTA PATRA, S. NEOGY, A. LAIK, S.K. CHOUDHARY, \\ and DEBALAY CHAKRABARTI
}

\begin{abstract}
Spatial distribution in size and frequency of microalloy precipitates have been characterized in two continuous-cast high-strength, low-alloy steel slabs, one containing $\mathrm{Nb}, \mathrm{Ti}$, and $\mathrm{V}$ and the other containing only Ti. Microsegregation during casting resulted in an inhomogeneous distribution of $\mathrm{Nb}$ and $\mathrm{Ti}$ precipitates in as-cast slabs. A model has been proposed in this study based on the detailed characterization of cast microalloy precipitates for predicting the spatial distribution in size and volume fraction of precipitates. The present model considers different models, which have been proposed earlier. Microsegregation during solidification has been predicted from the model proposed by Clyne and Kurz. Homogenization of alloying elements during cooling of the cast slab has been predicted following the approach suggested by Kurz and Fisher. Thermo-Calc software predicted the thermodynamic stability and volume fraction of microalloy precipitates at interdendritic and dendritic regions. Finally, classical nucleation and growth theory of precipitation have been used to predict the size distribution of microalloy precipitates at the aforementioned regions. The accurate prediction and control over the precipitate size and fractions may help in avoiding the hot-cracking problem during casting and selecting the processing parameters for reheating and rolling of the slabs.
\end{abstract}

DOI: $10.1007 / \mathrm{s} 11661-011-1045-9$

(C) The Minerals, Metals \& Materials Society and ASM International 2012

\section{INTRODUCTION}

CARBIDE, nitride, or carbonitride precipitates formed by the microalloying elements such as, $\mathrm{Nb}, \mathrm{Ti}$, and $\mathrm{V}$ provide grain refinement and precipitation strengthening in high-strength, low-alloy (HSLA) steel. ${ }^{[1]}$ Microalloy precipitates in continuous-cast slab can influence the microstructural changes taking place during subsequent processing such as reheating and rolling and, hence, need to be studied. Industrial reheating of HSLA steel is aimed at dissolving the $\mathrm{Nb}$ precipitates to encourage the fine-scale, strain-induced $\mathrm{Nb}(\mathrm{C}, \mathrm{N})$ precipitation during hot rolling. ${ }^{[1,2]}$ Pinning of austenite $(\gamma)$ grain boundaries by the microalloy precipitates also prevents the excessive $\gamma$ grain growth during soaking. ${ }^{[1,3]}$ The choice of reheating temperature and time, therefore, should be based on the characterization of as-cast precipitates. ${ }^{[1,3,4]}$

SUPARNA ROY, Ph.D. Student, SUDIPTA PATRA, M.S. Student, and DEBALAY CHAKRABARTI, Assistant Professor, are with the Department of Metallurgical and Materials Engineering, Indian Institute of Technology (I.I.T.), Kharagpur 721 302, West Bengal, India. Contact e-mail: debalay@metal.iitkgp.ernet.in S. NEOGY and A. LAIK, Scientists, are with the Materials Science Division, Bhabha Atomic Research Centre, Mumbai 400 085, India. S.K. CHOUDHARY, Researcher, is with the Research and Development, Tata Steel, Jamshedpur 831 007, Jharkhand, India.

Manuscript submitted May 26, 2011.

Article published online January 10, 2012
The nature, shape, and size of the microalloy precipitates have been widely investigated in as-cast slab as well as in thermomechanically controlled rolled (TMCR) HSLA steel plates/strips. ${ }^{[4-20]}$ Both macroand microsegregation during casting may result in an inhomogeneous distribution of the precipitates. ${ }^{[7-11,16-20]}$ The formation of large $(>1 \mu \mathrm{m})$ Nb-rich dendritic precipitates $^{[7,8,16,17]}$ or eutectic $(\mathrm{Nb}, \mathrm{Ti}, \mathrm{V})(\mathrm{C}, \mathrm{N})$ particles $^{[11]}$ in the interdendritic boundaries indicated the segregation of microalloying elements, especially $\mathrm{Nb}$. A higher volume fraction of $\mathrm{Nb}$ precipitates in pearlitic regions, which coincided with the interdendritic regions, compared with the ferritic regions, which coincided with the dendrite-center regions of TMCR steels containing 0.023 to $0.057 \mathrm{wt}$ pet $\mathrm{Nb}$, also has been attributed to interdendritic segregation. ${ }^{[18]}$

Clustering of coarse microalloy precipitates (such as dendritic $(\mathrm{Nb}, \mathrm{Ti})(\mathrm{C}, \mathrm{N})$ and $\mathrm{TiN}))$ in the interdendritic region of as-cast slab can lead to slab-surface cracking during continuous casting..$^{[9,21,22]}$ Hence, prediction and control over precipitate size and spatial distribution of precipitates is crucial for maintaining the cast-slab quality. The effect of segregation on the stability of microalloy precipitates and on the precipitate size distributions at different regions (solute-rich and solute-depleted) of as-cast slab is not well understood. Hence, a model has been proposed here, based on the detailed characterization of cast microalloy precipitates, for predicting the spatial distribution in size and volume fraction of precipitates. The present model considers different models, which have been proposed earlier. 
Microsegregation during solidification has been predicted from the model proposed by Clyne and Kurz. ${ }^{[23]}$ Homogenization of alloying elements during cooling of the cast slab has been predicted following the approach suggested by Kurz and Fisher. ${ }^{[2]}$ Thermo-Calc software predicted the thermodynamic stability and volume fraction of microalloy precipitates at interdendritic and dendritic regions. Finally, classical nucleation and growth theory of precipitation have been used to predict the size distribution of microalloy precipitates at the aforementioned regions. The predictions were verified by the measurement of the local composition and characterization of precipitates from interdendritic and dendritic regions of the as-cast slabs.

\section{EXPERIMENTAL DETAILS}

Two as-continuously cast (200 -mm thick and 1200 $\mathrm{mm}$ wide) low-carbon microalloyed steel slabs have been investigated. The chemical compositions of the two slabs are given in Table I.

Slab 1 contained microalloying elements $\mathrm{Nb}$, Ti, and $\mathrm{V}$, whereas Slab 2 did not contain any $\mathrm{Nb}$ and $\mathrm{V}$, but the concentration of $\mathrm{Ti}$ was twice that of Slab 1. As the investigated slabs were continuously cast commercial grades, the detailed time-temperature data during solidification was not available.

Through thickness slices $(200 \mathrm{~mm} \times 100 \mathrm{~mm} \times$ $25 \mathrm{~mm}$ ) were cut from the midwidth location of the continuously cast slabs. All microstructural specimens were collected from the top half of the slabs, at subsurface (SS, 0 to $20 \mathrm{~mm}$ from top surface), quarter-thickness (QT 40 to $60 \mathrm{~mm}$ from the top surface), and midthickness (MT, 90 to $110 \mathrm{~mm}$ from top surface) locations.

Standard techniques have been followed for metallographic sample preparations. The microstructural characterization in terms of secondary dendritic arm spacing (SDAS); second-phase fraction; and shape, size, and distribution of coarse- and fine-microalloy precipitates

Table I. Chemical Compositions of the Investigated Slabs

\begin{tabular}{lccccccrrr}
\hline Wt Pct & C & Si & Mn & P & S & Al & Nb & Ti & V \\
\hline Slab 1 & 0.09 & 0.33 & 1.42 & 0.010 & 0.003 & 0.035 & 0.050 & 0.019 \\
Slab 2 & 0.07 & 0.18 & 1.20 & 0.012 & 0.005 & 0.034 & - & 0.041 & - \\
\hline
\end{tabular}
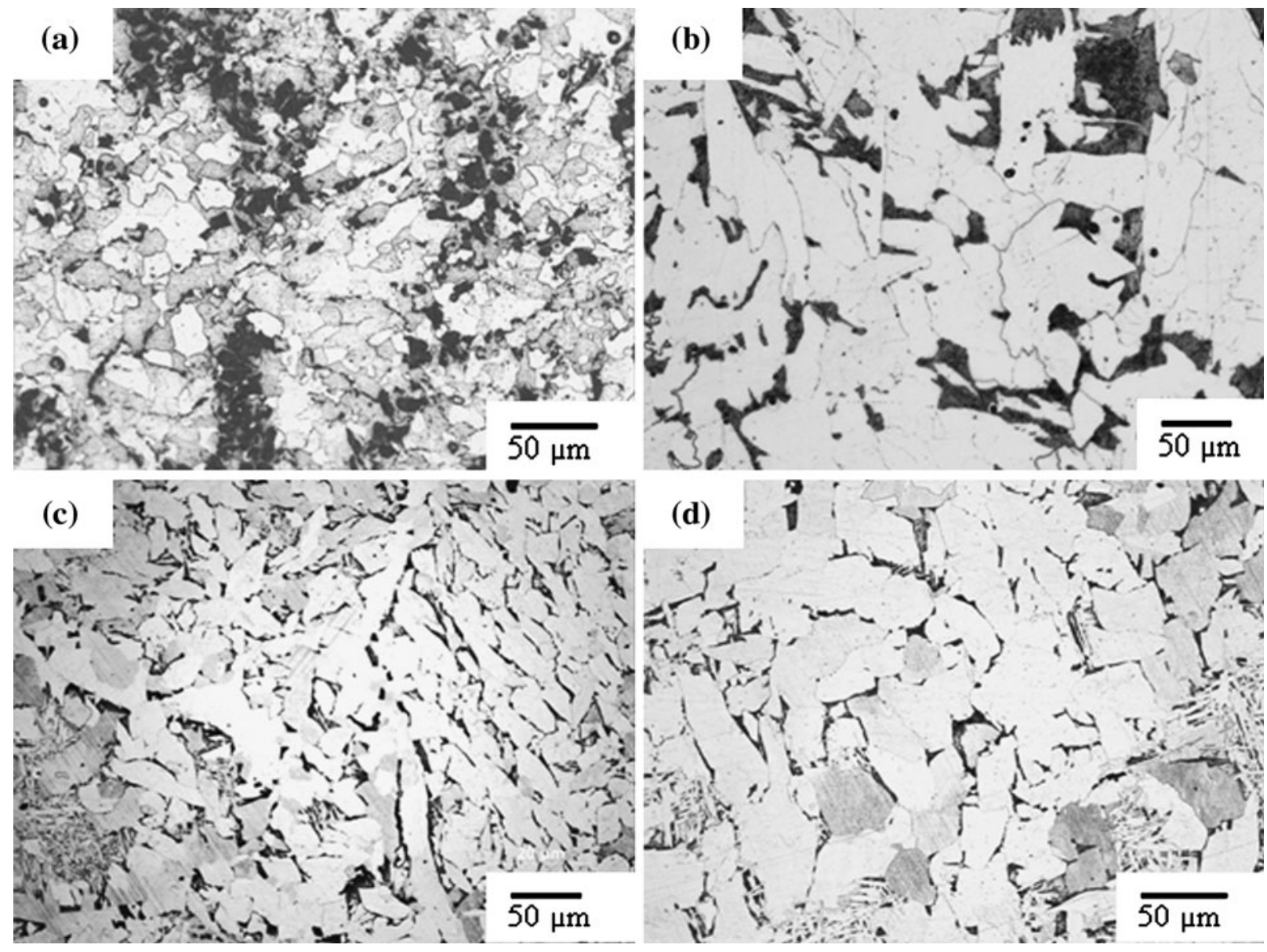

Fig. 1-Microstructures at the (a) SS and (b) QT locations of Slab 1 and at the (c) SS and (d) QT locations of Slab 2. 
have been carried out using a LEICA DM6000M optical microscope, fitted with Leica M.W. and Leica L.A.S. image analysis software (Leica Microsystems Gmbh,

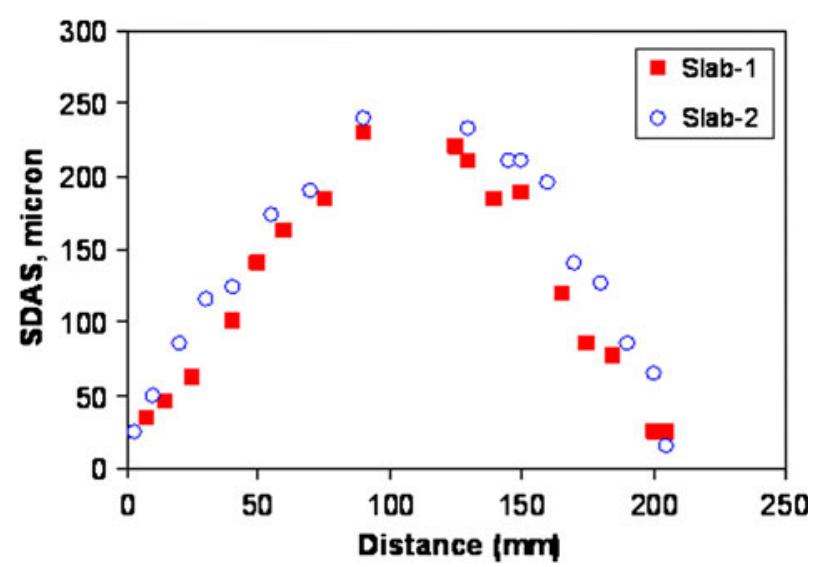

Fig. 2-Variation in SDAS through the thickness of the investigated slabs.
Wettzlar, Germany), as well as using Zeiss EVO 60 (Carl Zeiss MicroImaging, LLC, Thornwood, NY) and JEOL*

*JEOL is a trademark of Japan Electron Optics Ltd., Tokyo.

7300 model scanning electron microscopes (SEMs), fitted with Oxford-Inca PENTA FETX3 software (Oxford Instrument PLC, Abingdon, Oxfordshire, United Kingdom) for energy-dispersive X-ray spectroscope (EDS). At least 100 precipitates have been studied from each microstructural region (interdendritic/dendrite center) of every sample for calculating the average precipitate size. Fine precipitates $(>100 \mathrm{~nm})$ were characterized under JEOL 2000FX and JEOL ZEM-2100* model transmission electron microscopes (TEMs). Local compositions from interdendritic and in dendrite center regions at QT and MT locations of as-cast slabs have been detected by an electron probe microanalyzer (EPMA), equipped with three wavelength dispersive spectrometers (Cameca SX 100, CAMECA, Société par Actions Simplifiée (SAS), Gennevilliers Cedex, France).
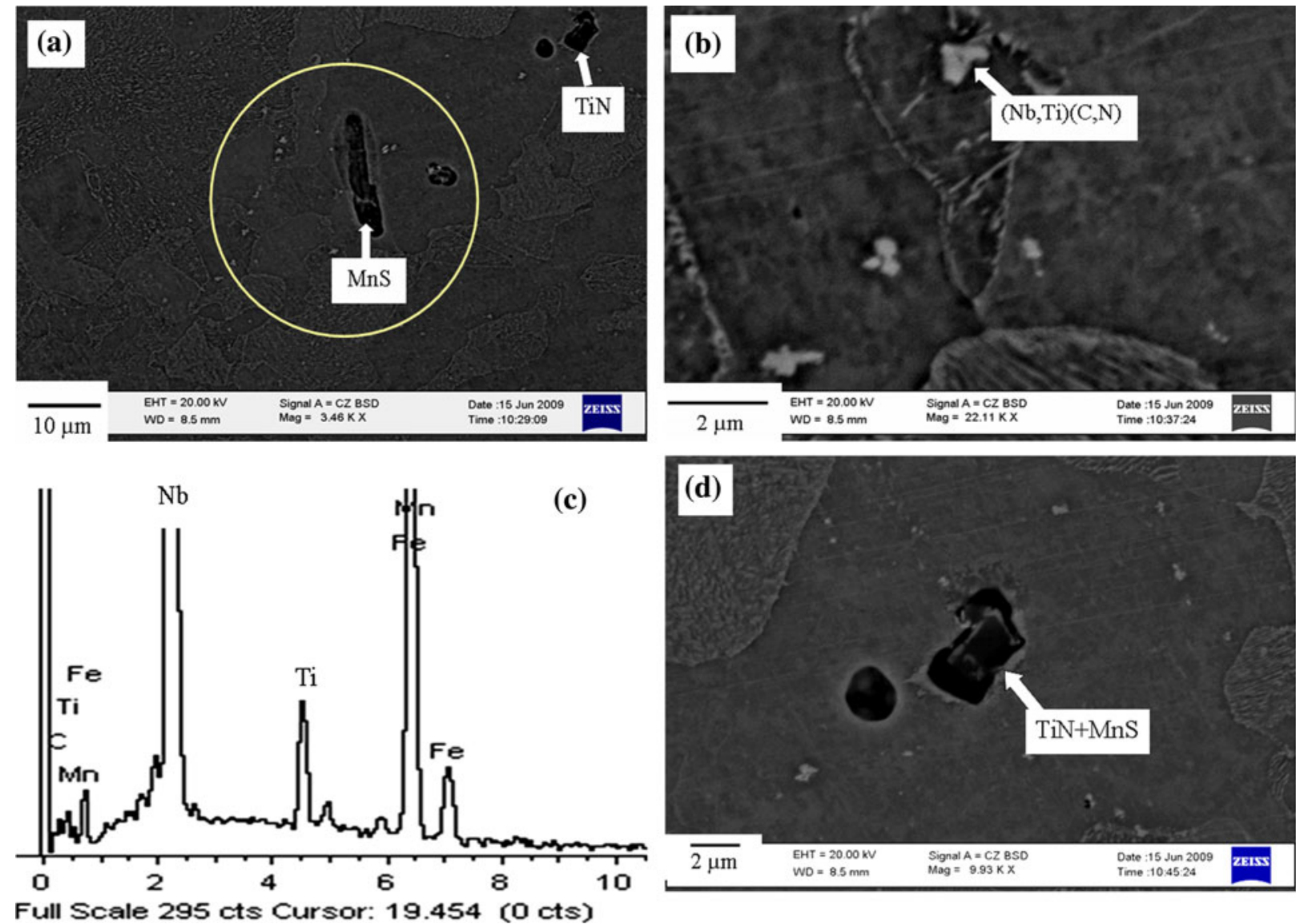

Full Scale 295 cts Cursor: 19.454 (o cts)

Fig. 3-(a) Inhomogeneous distribution of precipitates and inclusions (arrowed) at the QT location of Slab 1, showing a precipitate-rich region (circled) surrounded by precipitate-lean regions; $(b)$ a closer look at the bright precipitates in (a) and the corresponding EDS analysis in $(c)$, indicating the presence of $\mathrm{Nb}$ and $\mathrm{Ti}$ (possibly $(\mathrm{Nb}, \mathrm{Ti})(\mathrm{C}, \mathrm{N})$ ); $(d)$ cuboidal TiN particle formed on top of an MnS inclusion. 


\section{MICROSTRUCTURE AND PRECIPITATES IN AS-CAST SLABS}

\section{A. Microstructure of As-Cast Slabs}

The microstructures from SS, QT, and MT locations of as-continuously cast slabs consisted of ferrite and pearlite ( $\sim 15$ to $20 \mathrm{pct})$, Figure 1 . Ferrite grain sizes and SDAS increased from SS (Figures 1(a) and (c)) to QT (Figures 1(b) and (d) and to MT locations, possibly because of the decrease in slab cooling rate. The number-averaged SDAS values measured until the narrow, equiaxed zone $(\sim 25-\mathrm{mm}$ thick $)$ at the slab centerline in both slabs are given in Figure 2. The mean ferrite grain sizes (measured in equivalent circle diameter) were 20 to $25 \mu \mathrm{m}$ at SS, 35 to $40 \mu \mathrm{m}$ at QT, and 55 to $60 \mu \mathrm{m}$ at MT.

\section{B. Precipitates in the As-Cast Slab 1}

QT location ( $\sim 50-\mathrm{mm}$ below the top surface) was selected for detail precipitate quantification and detection of local compositions, as previous studies ${ }^{[4,20]}$ reported a consistent segregation profile at that location. An inhomogeneous distribution of precipitates was found on the polished surface of both investigated slabs, with precipitate-rich regions (circled in Figure 3(a)) surrounded by regions of low precipitate density (Figure 3(a)). The bright precipitates in Figure 3(a) are magnified in Figure 3(b), and the corresponding EDS analysis (Figure 3(c)) revealed them to be Nb-rich carbonitrides (either $\mathrm{Nb}(\mathrm{C}, \mathrm{N})$ or $(\mathrm{Nb}, \mathrm{Ti})(\mathrm{C}, \mathrm{N})$ ). Darker constituents in Figure 3(a) were either MnS inclusions or cuboidal TiN particles (Figure 3(d)). The brighter and darker appearances of the precipitates (or inclusions) in compositional contract of back-scattered electron images (Figures 3(a) and (b) are caused by their higher or lower (average) atomic numbers, respectively, compared with the Fe matrix. A fraction of Nb-rich precipitates, $\mathrm{MnS}$ and $\mathrm{TiN}$, were much higher in interdendritic regions (on or around the pearlite and bainite) compared with the dendrite center (ferrite) regions. The separation between subsequent precipitaterich regions (center-to-center distance of 140 to $160 \mu \mathrm{m}$ ) at the QT location was consistent with the SDAS values measured at that location $(\sim 150 \mu \mathrm{m})$. This observation indicates that interdendritic segregation was responsible for the inhomogeneous distribution of the precipitates and inclusions, with precipitate-rich regions being the interdendritic regions and precipitate-lean regions being the dendrite center regions

The shape and size of various microalloy precipitates observed in Slab 1 were as follows: (1) cuboidal TiN particles (700 to $1800 \mathrm{~nm}$ ), (2) star- or cruciform-shaped (winged) precipitates $(\mathrm{Nb}, \mathrm{Ti})(\mathrm{C}, \mathrm{N})(40$ to $1300 \mathrm{~nm}),(3)$ cuboidal-shaped $(\mathrm{Nb}, \mathrm{Ti})(\mathrm{C}, \mathrm{N})(30$ to $700 \mathrm{~nm})$, and (4) spherical $\mathrm{NbC}$ and $\mathrm{VC}$ (3 to $50 \mathrm{~nm}$ ). The frequency of spherical precipitates $(\sim 75 \mathrm{pct})$ was much higher
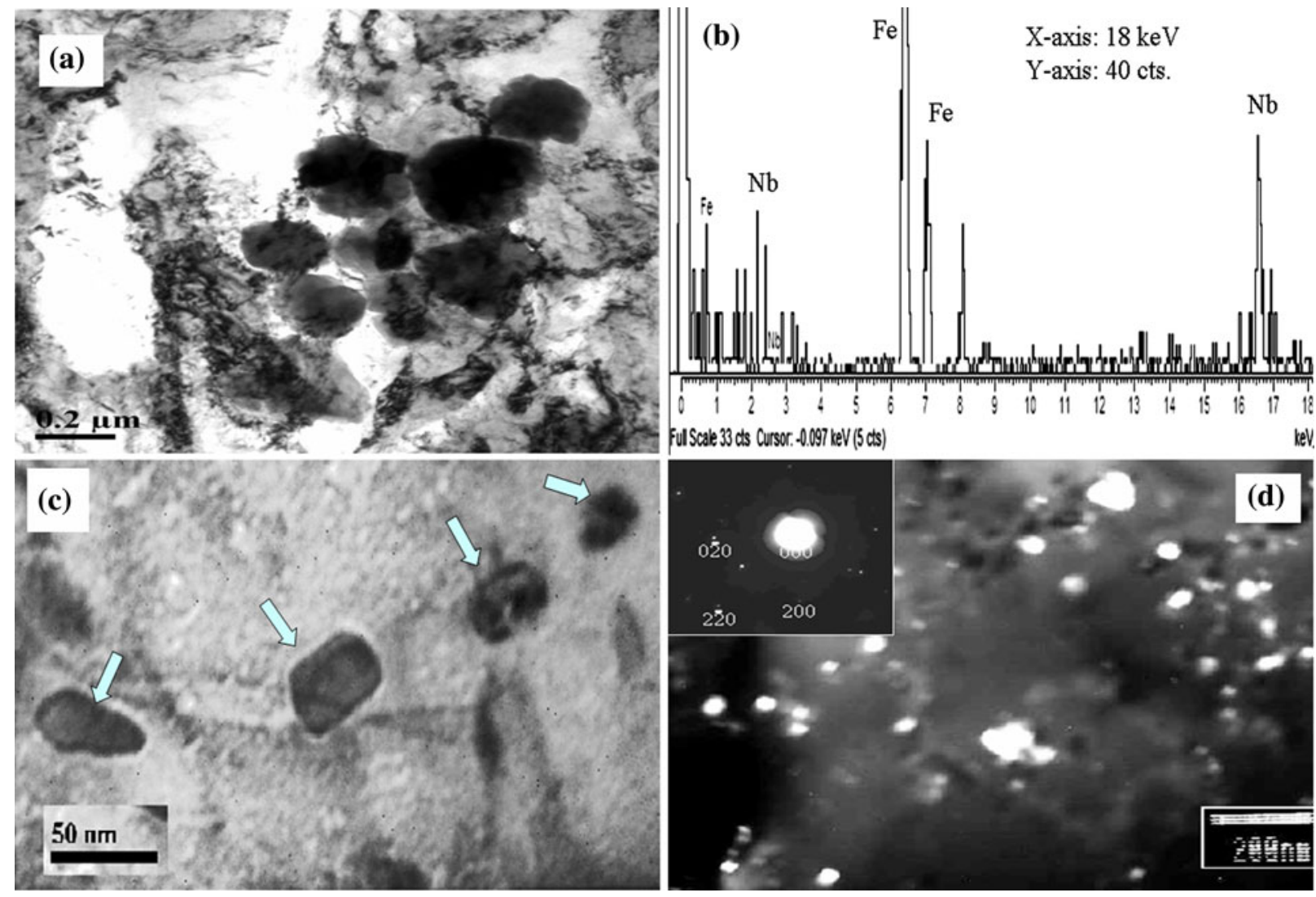

Fig. 4 - (a) Local clustering of Nb precipitates and (b) EDS spectrum taken from a precipitate in (a) showing an Nb peak. (c) Alignment of Nbrich precipitates (indicated by arrows) in Slab 1. (d) Dark-field image showing fine, VC precipitates $(<50 \mathrm{~nm})$ with SAD analysis. 
compared with cuboidal ( 10 pct) and star/cruciform precipitates $(\sim 15 \mathrm{pct})$. Star/cruciform-shaped particles were predominantly observed in interdendritic regions, which can be attributed to the microseregation-induced precipitation. ${ }^{[4,7,16-20]}$ Grouping/clustering of $\mathrm{Nb}$-rich precipitates is evident in Figures 4(a) and (b). $\mathrm{Nb}$ precipitates were also observed in rows, Figures 3(a) and 4(c)), which can be attributed to the rejection of solute atoms from the interdendritic melts, as the liquid melt front advanced during solidification. ${ }^{[16]}$ An EDS line scan confirmed that the distances between such "interdendritic precipitate bands" were consistent with the SDAS. Selected area diffraction (SAD) analysis was also carried out in TEM to identify the nature of the microalloy precipitates. For example, Figure 4(d) shows the SAD pattern for VC precipitates. Spherical VC and $(\mathrm{Nb}, \mathrm{V}) \mathrm{C}$ precipitates $(<30 \mathrm{~nm})$, however, were uniformly distributed throughout the ferrite matrix (Figure 4(d)).

\section{Precipitates in As-Cast Slab 2}

Similar to Slab 1, TiN particles in Slab 2 were present at a higher density in interdendritic regions (Figure 5(a)) compared with dendrite center regions (Figure 5(b)). The wide variation in cuboidal TiN particle sizes $(30 \mathrm{~nm}$ to $7 \mu \mathrm{m})$ can be reflected by the presence of large and small particles (Figures 5(a) through (d)). A Ti peak is visible in the EDS analysis collected from the large TiN particle in Figure 5(a). A dark-field (TEM) image showing a TiN particle and the corresponding SAD analysis is shown in Figure 5(d). The inhomogeneous distribution of TiN can be attributed to the microsegregation of Ti and $\mathrm{N}^{[7,8,17]}$ AlN particles have not been found in either slab possibly because of the presence of sufficient $\mathrm{Ti}$ for combining with all the $\mathrm{N}$ present in steels.

\section{Complex Precipitates and Microalloy Segregation at $M T$}

The heterogeneous precipitation of $(\mathrm{Nb}, \mathrm{Ti})(\mathrm{C}, \mathrm{N})$ in Slab 1 on the MnS inclusion (Figure 6(a)) and TiN in Slab 2 on the $\mathrm{Al}_{2} \mathrm{O}_{3}$ inclusion (Figure 6(b)) can be outcomes of microsegregation. ${ }^{[17]}$ Such complex particles may hamper the mechanical properties (such as ductility and low-temperature impact toughness) of the slabs. ${ }^{[17,21,22]}$ Microalloy segregates as large as 10 to $15 \mu \mathrm{m}$ of $\mathrm{Nb}$-rich $(\mathrm{Nb}, \mathrm{Ti})(\mathrm{C}, \mathrm{N})$ (Figures 7 (a) and (b)) and Ti-rich $(\mathrm{Nb}, \mathrm{Ti})(\mathrm{C}, \mathrm{N})$ (Figures $7(\mathrm{c})$ and (d)) were found at the MT location of Slab 1. The segregation of $\mathrm{Nb}$-rich $(\mathrm{Nb}, \mathrm{Ti})(\mathrm{C}, \mathrm{N})$ was associated with $\mathrm{MnS}$ inclusions (Figure 7(a)). The formation of large, eutectic $(\mathrm{Nb}, \mathrm{Ti})(\mathrm{C}, \mathrm{N})$ has been reported earlier in HSLA steel, ${ }^{[11]}$ which can also be attributed to the macrosegregation of $\mathrm{Nb}$ and $\mathrm{Ti}$. However, the presence of Ti-rich
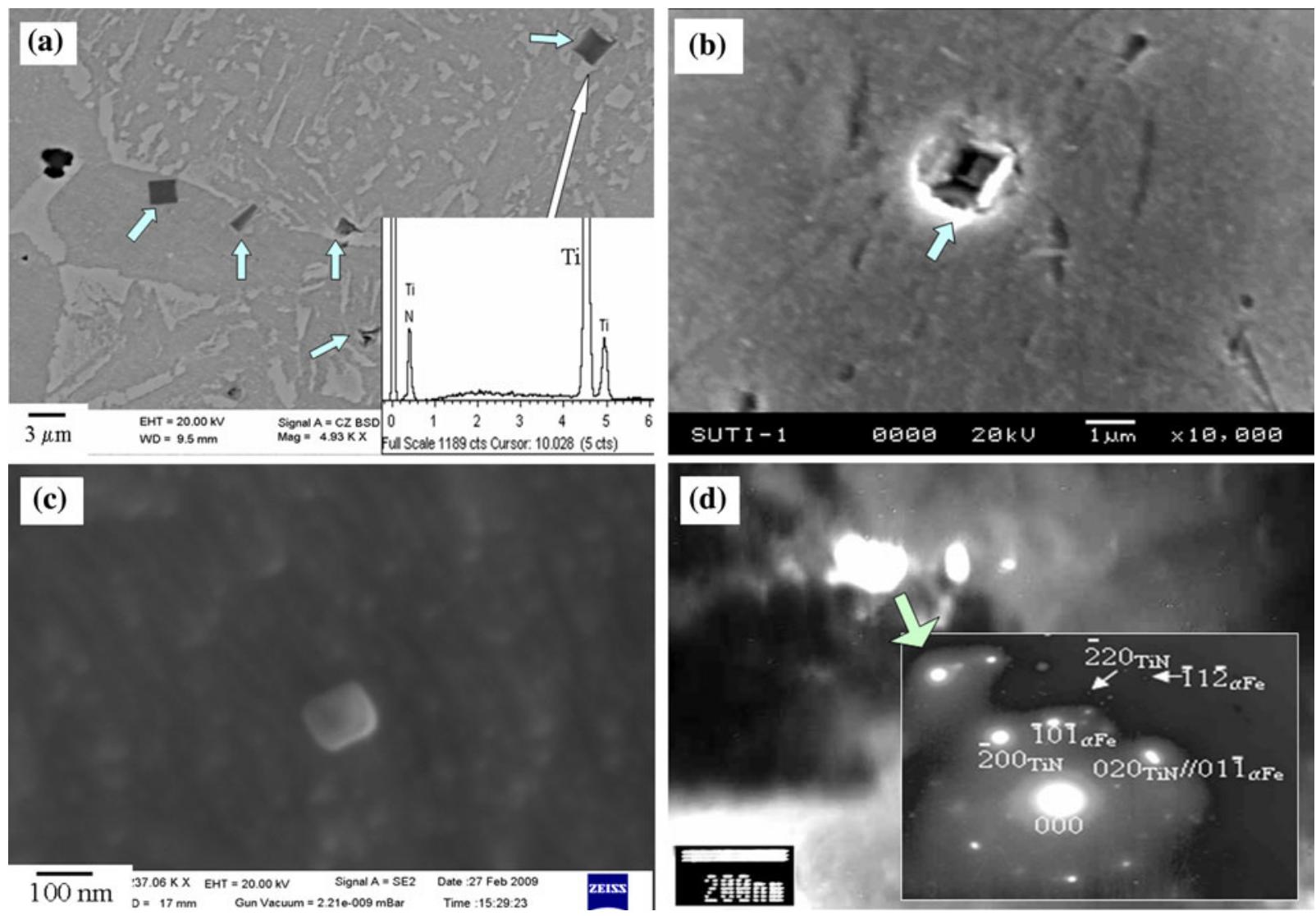

Fig. 5-Inhomogeneous distribution of TiN particles in Slab 2, with $(a)$ a high density of TiN (arrowed) in the interdendritic (pearlite + bainite) region and $(b)$ isolated TiN cuboid in the dendrite center (ferrite) region. EDS analysis showing Ti and N peaks in (a). Fine, cuboidal TiN particles $(<100 \mathrm{~nm})$ as observed in $(c)$ SEM image and $(d)$ dark-field TEM image, with the corresponding SAD analysis. 
$(\mathrm{Nb}, \mathrm{Ti})(\mathrm{C}, \mathrm{N})$ besides $\mathrm{Nb}$-rich segregates has not been reported earlier. Such constituents may also hamper the mechanical properties at the centerline of the as-cast slab.

\section{E. Fraction of Microalloy Precipitates in the As-Cast Slabs}

The number-density of microalloy precipitates was $\sim 2$ to 3 times higher at interdendritic (i.e., precipitate-rich) regions compared with the dendrite center (i.e., precipitate-poor) regions in each slab (Figure 8), indicating the microsegregation-induced inhomogeneous precipitate distribution. A greater $\mathrm{Ti}$ content in Slab 2 possibly resulted in larger TiN particles in Slab 2 (up to $\sim 7 \mu \mathrm{m}$ ), than that in Slab 1 (up to $\sim 1.8 \mu \mathrm{m}$ ). The number densities (number $/ \mathrm{mm}^{2}$ ) and average sizes (nm) of microalloy precipitates measured at SS, QT, and MT locations of each slab (Table II) indicate that precipitate densities and sizes increased from the SS toward the MT possibly because of the following reasons: (1) the increase in solute level caused by macrosegregation and (2) the slower cooling rate toward the slab center, allowing for more time for precipitate growth.

The higher precipitate density in Slab 1 compared with Slab 2 (Figure 8, Table II) can be attributed to the presence of $\mathrm{Nb}$ and $\mathrm{V}$, which formed numerous, fine $\mathrm{NbC}, \mathrm{VC}$, and $(\mathrm{Nb}, \mathrm{V}) \mathrm{C}$ precipitates in Slab 1.

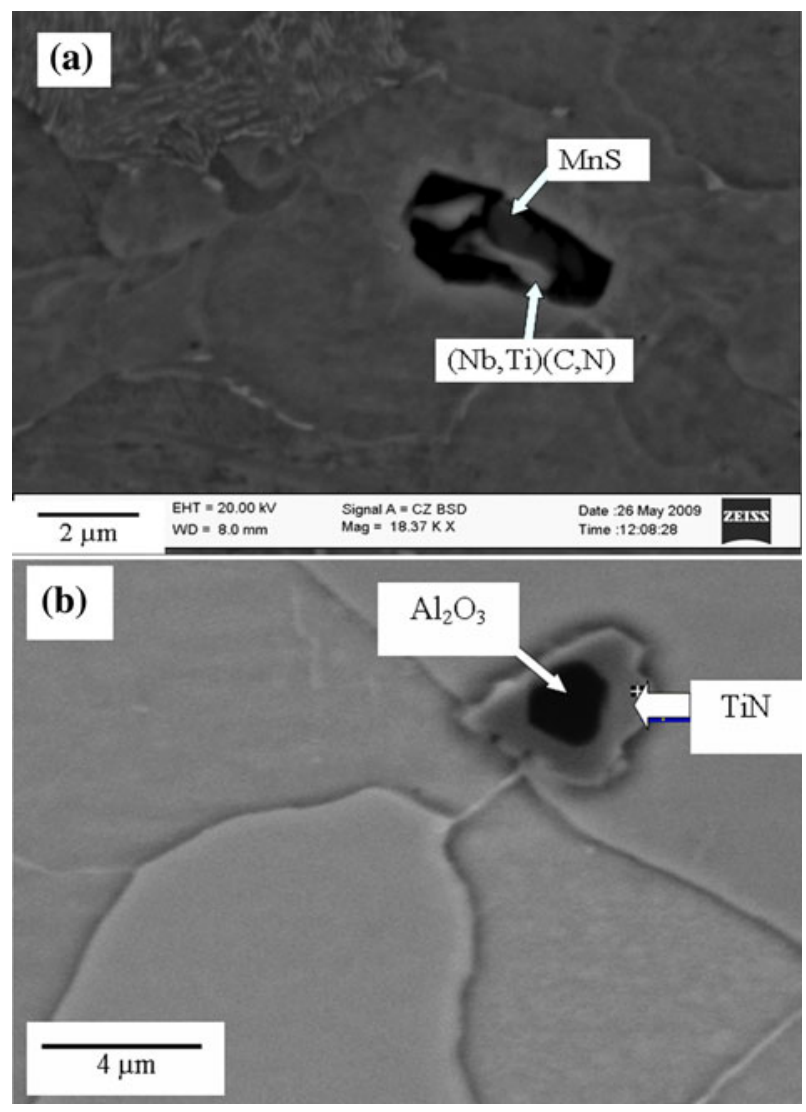

Fig. $6-(a)(\mathrm{Nb}, \mathrm{Ti})(\mathrm{C}, \mathrm{N})$ precipitates (appearing bright) forming on $\mathrm{MnS}$ (appearing dark) in Slab 1 and $(b)$ TiN particle forming around $\mathrm{Al}_{2} \mathrm{O}_{3}$ (appearing dark) inclusions in Slab 2.

\section{F. Measurement of Local Compositions in Interdendritic and Dendrite Center Regions}

The concentration of alloying elements (in wt pct) was measured by microanalysis of the interdendritic and dendrite center regions at the QT location of Slabs 1 and 2 using EPMA (Table III).

Wave-length dispersive X-ray spectroscope (WDS) was preferred in this case because of its high accuracy, especially for low atomic number elements. Table III clearly suggests that interdendritic regions were soluterich and dendrite-center regions were solute-depleted. Elements such as $\mathrm{Nb}, \mathrm{Ti}, \mathrm{P}, \mathrm{S}$, and $\mathrm{Mn}$ were clearly partitioned between the aforementioned regions. $\mathrm{C}$ and $\mathrm{N}$ levels were also higher in interdendritic regions than those in the dendrite center regions (Table III). Elements such as $\mathrm{Si}, \mathrm{V}$, and $\mathrm{Al}$ were distributed homogeneously throughout the matrix.

\section{THEORETICAL ANALYSIS}

\section{A. Dependence of Microsegregation on the Solidification Sequence}

According to the Thermo-Calc software, solidification in Slabs 1 and 2 is expected to start at around the same temperature $\left(\sim 1798 \mathrm{~K}\left[1425^{\circ} \mathrm{C}\right]\right.$ to $\left.1793 \mathrm{~K}\left[1520^{\circ} \mathrm{C}\right]\right)$ with the formation of $\delta$ ferrite (Figure 9(a)). Austenite starts to form at around $1758 \mathrm{~K}\left(1485^{\circ} \mathrm{C}\right)$ (Figure 9(a)). Complete solidification is predicted at $1730 \mathrm{~K}\left(1457^{\circ} \mathrm{C}\right)$ in Slab 1 and at $1718 \mathrm{~K}\left(1445^{\circ} \mathrm{C}\right)$ in Slab 2. Therefore, the freezing range of both slabs was similar; however, a slightly greater freezing range in Slab 2 (possibly because of its lower $\mathrm{C}$ level) might have promoted dendrite coarsening, which resulted in a slightly higher SDAS in Slab 2 than in Slab 1 (Figure 2). ${ }^{[25]}$

During thick-slab continuous casting, the metal in contact with the water-cooled copper mold (i.e., at the SS region) solidifies as the solute depleted $\delta$ ferrite (i.e., at the SS region). Solidification at the SS region will generally be completed as $\delta$ ferrite because of the increased cooling rate resulting in nonequilibrium solidification. ${ }^{[18]}$ Considering the subsequent $\delta \rightarrow \gamma$ transformation and decomposition of $\gamma$ into ferrite and pearlite, a greater microalloy precipitate size and number density of precipitates is expected in and around pearlite (or bainite) compared with the ferrite grain center regions, ${ }^{[18]}$ as found experimentally. At a greater depth (determined by slab composition and cooling rate) below the slab surface, the solidification sequence may change to mixed $\delta / \gamma$, which will result in different segregation behavior. The change in solidification sequence and associated spatial distribution of the microalloy precipitates have been discussed earlier in detail. $^{[18]}$

\section{B. Microsegregation Models}

Partitioning of various alloying elements between liquid and solid phases during equilibrium solidification can also be calculated from Thermo-Calc software (Thermo-Calc Software, Stockholm, Sweden). 

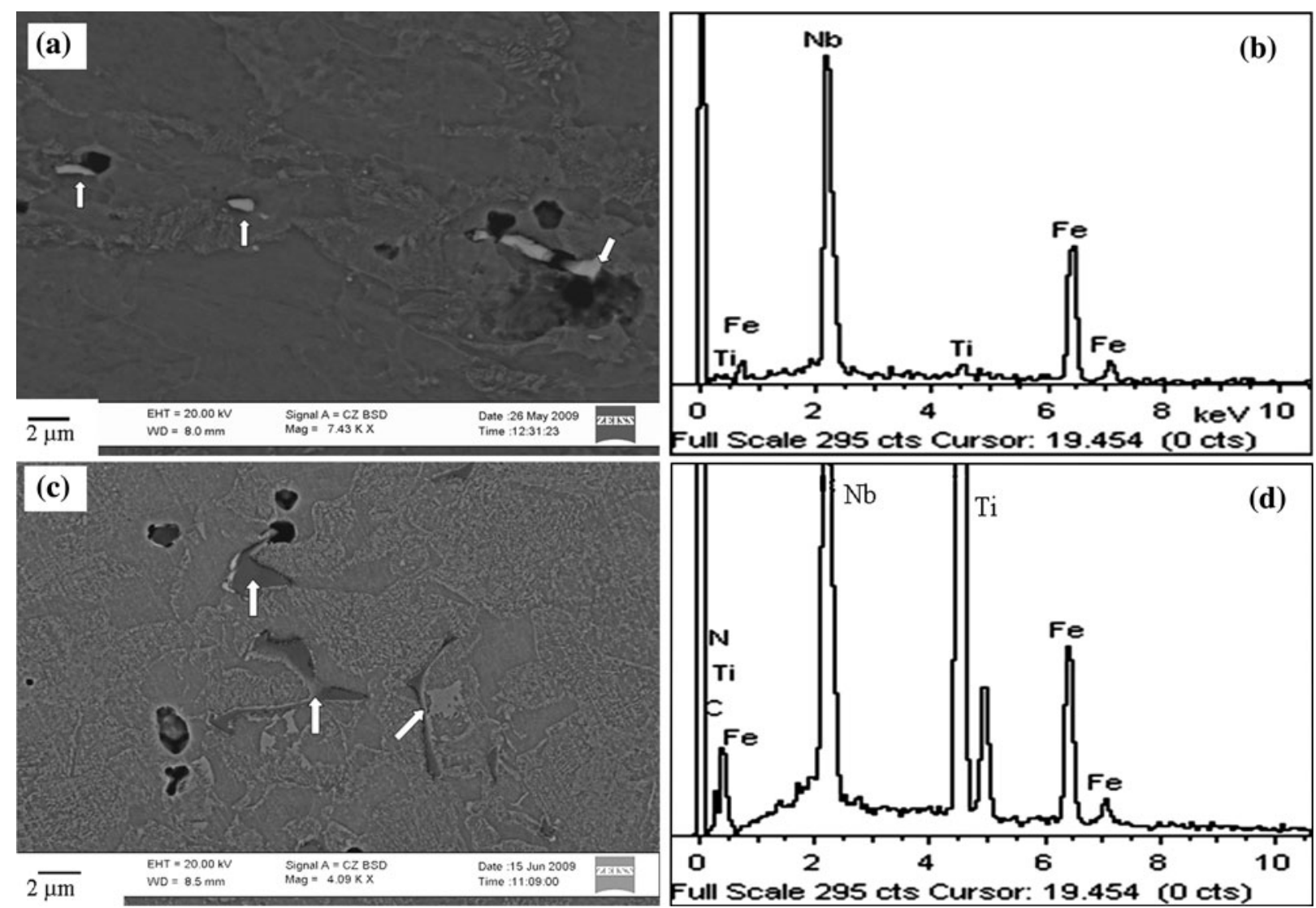

Fig. 7-(a) Large segregate with a brighter appearance (arrowed) showing the presence of $(b) \mathrm{Nb}$ and a small amount of Ti in its EDS spectrum; (c) segregate with a darker appearance (arrowed) containing a (d) large amount of Ti, besides $\mathrm{Nb}$, as evident from the EDS spectrum.

Thermo-Calc uses the following Scheil-Gulliver mod$\mathrm{el},{ }^{[26]}$ which is the simplest expression for calculating the solute redistribution in liquid $C_{\mathrm{L}}$ and in solid $C_{\mathrm{S}}$, considering the nominal composition of the steel $C_{0}$, and the weight fraction of solid $f_{\mathrm{S}}$ in the solidifying volume:

$$
C_{\mathrm{L}}=C_{0}\left(1-f_{\mathrm{S}}\right)^{k_{p}-1} \text { where, } k_{p}=\frac{C_{\mathrm{S}}}{C_{\mathrm{L}}}
$$

The equilibrium partition ratio $\left(k_{p}\right)$ of various alloying elements in steel are listed in Table IV,$^{[11,27,28]}$ for a different solidification route $(L \rightarrow L+\delta$ and $L \rightarrow$ $L+\gamma)$.

The prediction of solute partitioning indicates that the $\mathrm{Nb}$ level in the last solidifying liquid $\left(C_{\mathrm{L}}\right)$ can reach $\sim 6.0$ times of the average $\mathrm{Nb}$ level $\left(C_{0}\right)$ in steel (Figure $9(\mathrm{~b})$ ). $\mathrm{Ti}, \mathrm{C}$, and $\mathrm{N}$ showed $C_{\mathrm{L}} / C_{0}$ of $\sim 3.3$, $\sim 5.0$, and $\sim 2.6$, respectively. $\mathrm{S}$ showed the strongest partitioning with $C_{\mathrm{L}} / C_{0}$ of $\sim 20$, whereas elements such as $\mathrm{V}$ and $\mathrm{Al}$ showed negligible partitioning during solidification $\left(C_{\mathrm{L}} / C_{0}\right.$ of $\sim 1$ to 1.5$)$. This finding can explain the inhomogeneous distribution of $\mathrm{MnS}$ inclusions as well as $\mathrm{Nb}$ and $\mathrm{Ti}$ precipitates in the investigated slabs and the nearly homogeneous distribution of the $\mathrm{V}$ precipitates. However, the partitioning of alloying elements in the measured concentrations in Table III ( $\mathrm{Nb}$ level in interdendritic region: average $\mathrm{Nb}$ level $~ 1.6$ ) is smaller than that predicted by Thermo-Calc.
To better predict solute partitioning during solidification, compared with the lever rule and Scheil equation, Brody and Flemings ${ }^{[30]}$ proposed the following equation:

$$
C_{\mathrm{L}, i}=C_{0, i}\left[1-\left(1-2 \alpha k_{p}\right) f_{s}\right]^{\frac{\left(k_{p}-1\right)}{\left(1-2 \alpha k_{p}\right)}}
$$

where $C_{\mathrm{L}, i}$ is the liquid concentration of a given solute (e.g., $i)$ at the solid-liquid interface, $C_{0, i}$ is the initial liquid concentration, $k_{p}$ is the equilibrium partition coefficient of solute $i$, and $f_{\mathrm{s}}$ is the solid fraction. The equilibrium partition ratio $\left(k_{p}\right)$ of various alloying elements in steel are listed in Table IV, ${ }^{[11,27,28]}$ for a different solidification route $(\mathrm{L} \rightarrow \mathrm{L}+\delta$ and $\mathrm{L} \rightarrow \mathrm{L}+\gamma)$. The back-diffusion coefficient $\alpha$ is defined as follows:

$$
\alpha=\frac{D_{\mathrm{S}} t_{f}}{\left(0.5 \lambda_{\mathrm{S}}\right)^{2}}
$$

where $D_{\mathrm{S}}$ is the diffusion coefficient of solute in the solid phase (either $\delta$ ferrite or $\gamma$ ) in $\mathrm{cm}^{2} \mathrm{~s}^{-1}$ (Table IV), $\lambda_{\mathrm{S}}$ is the SDAS in $\mathrm{cm}$, and $t_{f}$ is the local solidification time (seconds), which is expressed as follows:

$$
t_{f}=\frac{T_{\mathrm{L}}-T_{\mathrm{S}}}{C_{\mathrm{R}}}
$$

where $T_{\mathrm{L}}$ and $T_{\mathrm{S}}$ are the liquidus and solidus temperatures of the steel (predicted using Thermo-Calc software) 


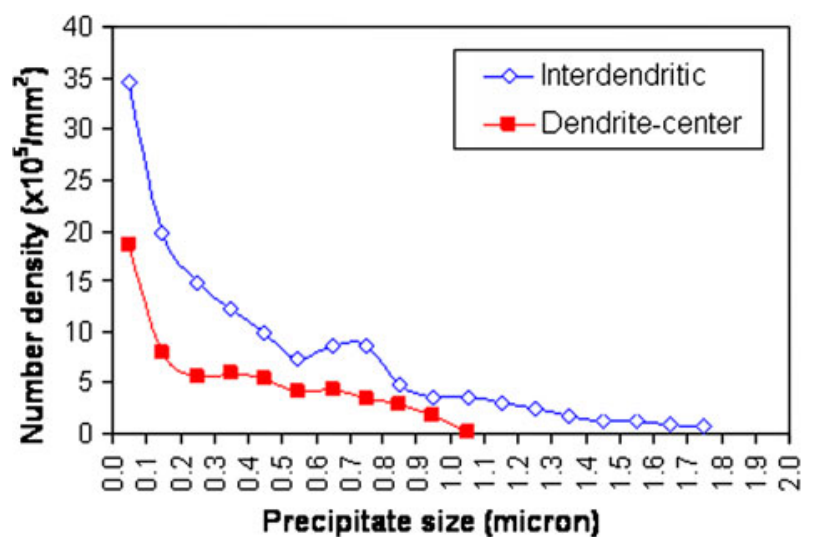

(a)

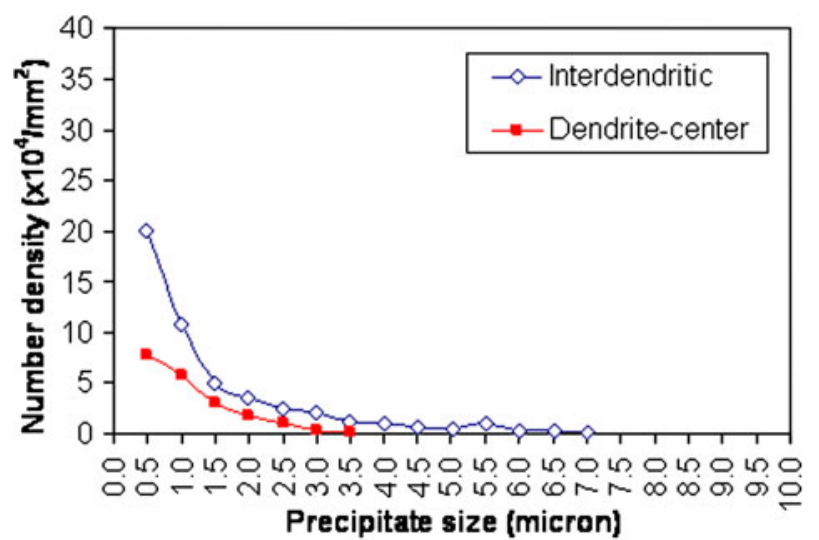

(b)

Fig. 8-Number densities for different sizes of microalloy precipitates in interdendritic and dendrite center regions of $(a)$ Slab 1 and (b) Slab 2.

Table II. Number Density (per $\mathbf{m m}^{2}$ ) and Average Size (nm) of Microalloy Precipitates Measured in Solute-Rich and Solute-Poor Regions at SS, QT, and MT Locations of Slab 1 and Slab 2

\begin{tabular}{llccccc}
\hline & & $\begin{array}{c}\text { Number Density } \\
\text { per } \mathrm{mm}^{2}\left(\times 10^{6}\right)\end{array}$ & & \multicolumn{2}{c}{$\begin{array}{c}\text { Average Size } \\
(\mathrm{nm})\end{array}$} \\
\cline { 3 - 4 } \cline { 6 - 7 } & & Steel 1 & Steel 2 & & Steel 1 & Steel 2 \\
\hline SS & solute-rich & 12 & 0.6 & & 35 & 70 \\
& solute-poor & 4 & 0.4 & & 20 & 50 \\
& average & 7 & 0.5 & & 25 & 60 \\
QT & solute-rich & 15 & 1.0 & & 50 & 88 \\
& solute-poor & 6 & 0.5 & & 30 & 45 \\
\multirow{3}{*}{ MT } & average & 10 & 0.7 & & 40 & 60 \\
& solute-rich & 18 & 2 & & 70 & 105 \\
& solute-poor & 8 & 0.4 & & 30 & 45 \\
& average & 13 & 0.9 & & 45 & 70 \\
\hline
\end{tabular}

and $C_{\mathrm{R}}$ is the average cooling rate during solidification, which can be obtained from the measured SDAS $\left(\lambda_{\mathrm{S}}\right)$ at any location of the slab using the following expres$\operatorname{sion}^{[31]}$ :

$$
\lambda_{\mathrm{S}}=\left(169.1-720.9 C_{0, \mathrm{C}}\right) C_{\mathrm{R}}^{-0.4935}
$$

where $C_{0, \mathrm{C}}$ is the nominal $\mathrm{C}$ content of the steel (for $\mathrm{C}$ $<0.15$ wt pct). Clyne and $\mathrm{Kurz}^{[23]}$ replaced the backdiffusion coefficient $(\alpha)$ in Eq. [2] with the term $\Omega$, which is defined as follows:

$$
\Omega=\alpha\left[1-\exp \left(-\frac{1}{\alpha}\right)\right]-\frac{1}{2} \exp \left(-\frac{1}{2 \alpha}\right)
$$

The Clyne and $\mathrm{Kurz}^{[23]}$ model is suitable for predicting the microsegregation in low-C steels. ${ }^{[29,30]}$ Using the measured SDAS values (Figure 2), the $C_{\mathrm{R}}$ and $t_{f}$ values can be calculated from Eqs. [4] and [5] for the following locations of the slabs: SS (i.e., $10 \mathrm{~mm}$ from the top surface): $C_{\mathrm{R}} \sim 4 \mathrm{~K} / \mathrm{s}$ and $t_{f} \sim 12$ seconds; QT: $C_{\mathrm{R}} \sim 1 \mathrm{~K} / \mathrm{s}$ and $t_{f} \sim 50$ seconds; and MT: $C_{\mathrm{R}} \sim 0.2 \mathrm{~K} / \mathrm{s}$ and $t_{f}$ $\sim 250$ seconds. The partitioning of microalloying elements $(\mathrm{Nb}, \mathrm{Ti}$, and $\mathrm{V})$ predicted from the Clyne and Kurz model ${ }^{[23]}$ at SS and MT locations (Figure 10) show that microsegregation becomes severe with an increase in depth below the SS. Following the previous studies, ${ }^{[21,32]}$ the composition in solid corresponding to solid fraction, $f_{\mathrm{s}} \sim 0.05$, and the composition in the liquid corresponding to $f_{\mathrm{s}} \sim 0.95$, are assumed to be the compositions at the middle of solute-depleted (dendrite center) regions and solute-rich (interdendritic) regions, respectively. The concentration of alloying elements predicted from the Clyne and Kurz model ${ }^{[23]}$ at interdendritic and dendrite center regions at the QT location in the slabs is listed in Table V.

The difference between predicted and measured concentrations (Tables III and V) can be caused by the fact that the Clyne and Kurz model ${ }^{[23]}$ predicts the solute partitioning during solidification without considering the homogenization taking place during the subsequent cooling of the slabs from solidus temperature to ambient temperature.

\section{Homogenization During Cooling of As-Cast Slab}

The change in the concentration profile resulting from microsegregation, during any homogenization treatment can be represented by the one-dimensional, time-dependent diffusion equation, and its likely solution can be expressed as follows ${ }^{[24]}$ :

$$
C(x, t)=C_{0}+\Delta C \cos \left(\frac{\pi x}{\lambda_{s}}\right) \exp \left(-\frac{t}{\tau}\right)
$$

where $C(x, t)$ is the solute concentration at any point corresponding to the interdendritic or dendrite center regions after homogenization for time $t$ at temperature $T$. $\mathrm{C}_{0}$ is the nominal composition of the steel, $\Delta C$ is the amplitude of the initial concentration profile, which is approximated as a cosine function, ${ }^{[24]} \lambda_{s}$ is the secondary dendritic arm spacing, $x$ is the distance along the direction perpendicular to the secondary dendritic arms, and $\tau$ is the relaxation time, which can be expressed as follows:

$$
\tau=\frac{\lambda_{s}^{2}}{\pi^{2} D_{s}}
$$


Table III. Concentrations of Various Elements (in wt pet) Obtained by Microanalysis of the Interdendritic and Dendrite Center Regions at Various Locations of Slab 1 and Slab 2 Using EPMA

\begin{tabular}{|c|c|c|c|c|c|c|c|c|c|c|}
\hline Elements & $\mathrm{C}$ & $\mathrm{Si}$ & $\mathrm{Mn}$ & $\mathrm{P}$ & $\mathrm{S}$ & $\mathrm{Al}$ & $\mathrm{Nb}$ & $\mathrm{Ti}$ & V & $\mathrm{N}$ \\
\hline \multicolumn{11}{|c|}{ Measured at QT of Slab 1} \\
\hline Interdendritic & 0.11 & 0.40 & 1.6 & 0.020 & 0.010 & 0.04 & 0.08 & 0.040 & 0.055 & 0.010 \\
\hline Dendrite center & 0.07 & 0.30 & 1.2 & 0.005 & 0.001 & 0.04 & 0.02 & 0.010 & 0.045 & 0.006 \\
\hline \multicolumn{11}{|c|}{ Measured at QT of Slab 2} \\
\hline Interdendritic & 0.11 & 0.30 & 1.4 & 0.020 & 0.010 & 0.03 & - & 0.06 & - & 0.11 \\
\hline Dendrite center & 0.08 & 0.20 & 1.1 & 0.004 & 0.001 & 0.03 & & 0.03 & & 0.005 \\
\hline
\end{tabular}

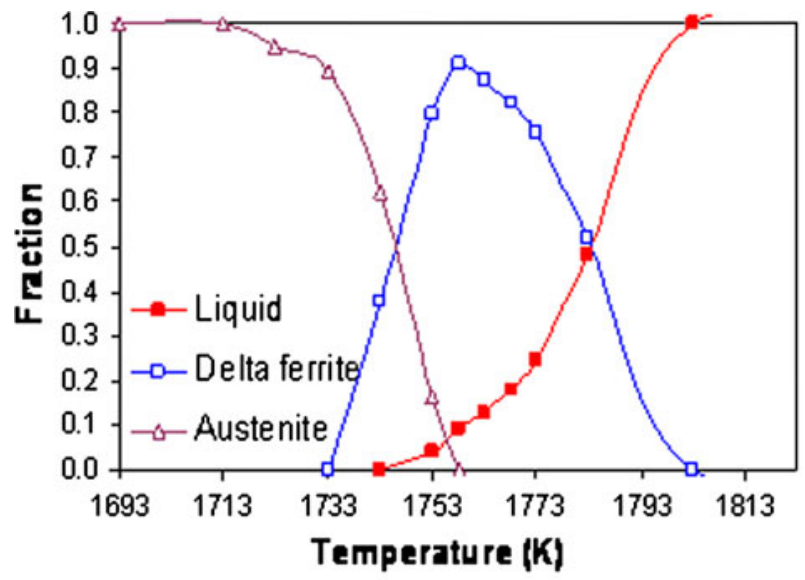

(a)

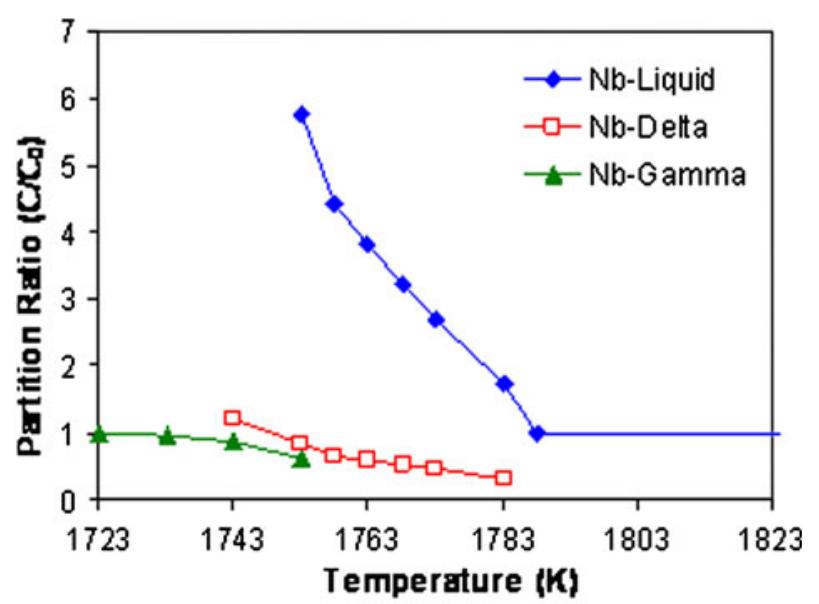

(b)

Fig. 9-(a) The solidification sequence in Slab 1 predicted by Thermo-Calc software. (b) Thermo-calc prediction of $\mathrm{Nb}$ partitioning among liquid, delta-ferrite, and austenite (gamma) during the solidification of Slab 1.

Starting with the predicted compositions at the end of solidification obtained from the Clyne and Kurz model ${ }^{[23]}$ in the middle of solute-rich (interdendritic) and solute-depleted (dendrite center) regions and assuming that the concentration profile follows a cosine function, the change in concentration at those regions during cooling has been calculated using Eq. [7]. Equations [7] and [8] are applicable to the isothermal holding condition, and the Additivity rule ${ }^{[33]}$ has been used for continuous cooling. Following the predicted solidification sequence (Figure 9(a)) as the solidification reaches the completion (i.e., $\left.f_{s}>0.95\right), \delta$ ferrite dominates the microstructure over a 5 to $10 \mathrm{~K}$ temperature range before $\delta$ transforms to $\gamma$. Because of the higher diffusivity of solutes in $\delta$ ferrite compared with $\gamma$ (Table IV), substitutional solutes (such as $\mathrm{Nb}$ and $\mathrm{Ti}$ ) are predicted to homogenize partly in $\delta$ ferrite, whereas negligible homogenization takes place within $\gamma$ (Figure 11(a)). Because of the high diffusivity, interstitial elements, such as $\mathrm{C}$ and $\mathrm{N}$, are expected to homogenize almost completely within the $\delta$ phase field (Figure 11(b)). The predicted concentration of alloying elements at the interdendritic and dendrite center regions at QT of both slabs, after the slabs cool to the ambient temperature (Table V), is close to the experimentally measured values listed in Table III. Solid-state homogenization was negligible during the solidification in austenitic route $(\mathrm{L} \rightarrow \mathrm{L}+\gamma)$, which might have occurred at the slab-center location, ${ }^{[18]}$ resulting is strong segregation that formed large microalloy deposits (Figure 7).

\section{Thermo-Calc Prediction of Precipitate Volume Fraction}

To predict the precipitate volume fraction separately in the interdendritic and dendrite center regions of the microsegregated slabs, the concentration of alloying elements at those regions, calculated from the Clyne and Kurz model ${ }^{[23]}$ (Table V) were fed into the Thermo-Calc software. Precipitates are expected to form at higher temperatures and at larger mole fractions in the soluterich (interdendritic) regions compared with those in the solute-depleted (dendrite center) regions (Figure 12). TiN particles are predicted to form initially in the interdendritic liquid during solidification followed by their precipitation in the solid state (Figures 12(a) and (b)). The Thermo-Calc prediction of the internal composition of precipitates suggests that TiN formed predominantly at a higher temperature and converted to $\operatorname{Ti}(\mathrm{C}, \mathrm{N})$ and then to $\mathrm{TiC}$ with the decrease in temperature. $\mathrm{Nb}$ precipitates were mainly carbides, which contained some $\mathrm{Ti}$ at higher temperatures. V precipitates formed at lower temperatures in $\gamma$, as well as in $\alpha$, were mainly VC. Ti combined with almost all of the $\mathrm{N}$ present in Slab 1 formed TiN, which resulted in the subsequent precipitation of fine microalloy carbides ( $\mathrm{NbC}$ and VC). VC precipitation is expected to be least affected by the microsegregation (Figure 12(a)), which agrees with the experimental observation. Similarly, in 


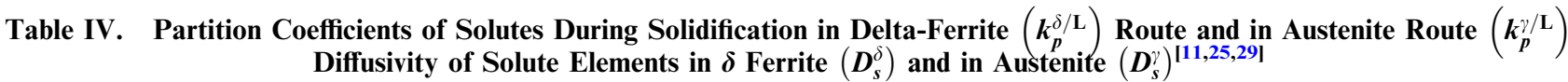

\begin{tabular}{lllll}
\hline Element & $k_{p}^{\delta / \mathrm{L}}$ & $k_{p}^{\gamma / \mathrm{L}}$ & $D_{s}^{\delta} \times 10^{4}\left(\mathrm{~m}^{2} / \mathrm{s}\right)$ & \multicolumn{1}{c}{$D_{s}^{\gamma} \times 10^{4}\left(\mathrm{~m}^{2} / \mathrm{s}\right)$} \\
\hline $\mathrm{C}$ & 0.19 & 0.34 & $0.0127 \exp (-81,379 / \mathrm{R} T)$ & $0.15 \exp (-143,511 / \mathrm{R} T)$ \\
$\mathrm{Si}$ & 0.77 & 0.79 & $8.0 \exp (-248,948 / \mathrm{R} T)$ & $0.30 \exp (-251,458 / \mathrm{R} T)$ \\
$\mathrm{Mn}$ & 0.77 & 0.60 & $0.76 \exp (-224,430 / \mathrm{R} T)$ & $0.055 \exp (-249,366 / \mathrm{R} T)$ \\
$\mathrm{Al}$ & 0.60 & 0.13 & $5.9 \exp (-96,441 / \mathrm{R} T)$ & $5.9 \exp (-241,417 / \mathrm{R} T)$ \\
$\mathrm{P}$ & 0.23 & 0.035 & $2.9 \exp (-230,120 / \mathrm{R} T)$ & $0.01 \exp (-182,841 / \mathrm{R} T)$ \\
$\mathrm{S}$ & 0.05 & 0.33 & $4.56 \exp (-214,639 / \mathrm{R} T)$ & $2.4 \exp (-223,426 / \mathrm{R} T)$ \\
$\mathrm{Ti}$ & 0.38 & 0.63 & $3.15 \exp (-247,693 / \mathrm{R} T)$ & $0.15 \exp (-250,956 / \mathrm{R} T)$ \\
$\mathrm{V}$ & 0.93 & 0.22 & $5.8 \exp (-239,994 / \mathrm{R} T)$ & $0.284 \exp (-250,956 / \mathrm{R} T)$ \\
$\mathrm{Nb}$ & 0.40 & 0.48 & $1.57 \exp (-243,509 / \mathrm{R} T)$ & $0.83 \exp (-266,479 / \mathrm{R} T)$ \\
$\mathrm{N}$ & 0.25 & 0.03 & $0.0371 \exp (-96,441 / \mathrm{R} T)$ & $0.91 \exp (-168,490 / \mathrm{R} T)$ \\
$\mathrm{O}$ & 0.03 & & $5.75 \exp (-168,615 / \mathrm{R} T)$ \\
\hline
\end{tabular}

Thermo-Calc, the predicted compositions of interdendritic liquid near the MT location indicated that large amount of $\mathrm{Ti}$ - and $\mathrm{Nb}$-rich particles are anticipated to form, which may explain the formation of large microalloy segregates (several micrometers in size, Figure 7). $\mathrm{MnS}$ inclusions were also predicted to form in the interdendritic melt, toward the end of solidification, and were expected to show inhomogeneous distribution. Using the density and molar volume of the precipitates (and Fe matrix) as listed in Table VI, ${ }^{[16]}$ the mole fractions of the precipitates predicted in Figure 12 have been converted to the corresponding volume fractions, which were close to those measured by image analysis (Figure 13).

\section{E. Prediction of Precipitate Size Distribution}

The sizes of oxide and sulfide inclusions and TiN particles have been predicted in earlier studies considering the microsegregation of alloying elements during solidification. ${ }^{[37-39]}$ The nucleation rate and growth-rate should remain constant in a homogeneously supersaturated metal, which is not the case for microsegregation. Hence, the nucleation and growth model have to be coupled with the microsegregation model to predict the size distribution of different precipitates in the interdendritic and dendrite center regions.

\section{Supersaturation and nucleation of microalloy} precipitates

The time-dependent homogeneous nucleation of spherical particles can be expressed as follows ${ }^{[40-43]}$ :

$$
I=N_{\mathrm{V}} Z \beta^{*} \exp \left(-\frac{\Delta G^{*}}{k T}\right) \exp \left(-\frac{\tau}{t}\right)
$$

where $N_{\mathrm{V}}$ is the number of nucleation sites per unit volume and $\Delta G^{*}$ is the energy required to form a nucleus of critical size $\left(r^{*}\right)$ and $\mathrm{kT}(\mathrm{k}$ is the Boltzmann constant and $\mathrm{T}$ is the absolute temperature in $\mathrm{K}$ ) and $t$ represents time. Expressions for calculating the Zeldovich factor $Z$, frequency factor $\beta^{*}$, and incubation time $\tau$, are given in References 40-43. Ignoring the strain energy, the critical nucleus size radius $r^{*}$ can be expressed as follows:

$$
r^{*}=-\frac{2 . \sigma}{\Delta G_{v}}
$$

where $\sigma$ is the interfacial energy of the nucleus and $\Delta G_{\mathrm{V}}$ is the volume free energy change during nucleation. Previous studies ${ }^{[32,38,39]}$ discussed in detail the modification of Eq. [9] for predicting the TiN precipitation in liquid steel. $\Delta G_{\mathrm{v}}$ can be obtained from the supersaturation ratio $\eta$ using the following equation:

$$
\eta=\frac{[\text { wt pct Ti }][\text { wt pct N]}}{L_{\mathrm{TiN}}}
$$

where $L_{\mathrm{TiN}}$ is the solubility product of TiN in liquid iron as given in Table VI. Interfacial energy $\sigma \sim 0.8 \mathrm{~J} / \mathrm{m}^{2}$ can be used for TiN precipitation in the liquid. ${ }^{[32,39,40]}$

From the previous equations, it is evident that a different level of supersaturation-resulting from microsegregation - in different regions of solidifying and solidified steel can result in different chemical driving forces $\left(\Delta G_{\mathrm{v}}\right)$ for precipitation between those regions. In the interdendritic region, higher $\Delta G_{\mathrm{v}}$ will increase the nucleation rate $I$ and reduce the critical nucleus size $\left(r^{*}\right)$. According to the present study, TiN precipitation in the interdendritic liquid starts at $\eta=\sim 5$ to 6 , which agrees with previous reports. ${ }^{[32,39,40]} \mathrm{A}$ continuous increase in $\eta$ for $\mathrm{TiN}$ in the solute-rich and solute-depleted regions in the QT location of Slab 2, with the decrease in temperature, is shown in Figure 14. The $\eta$ values have been calculated using the compositions determined by the Clyne and Kurz model ${ }^{[23]}$ for interdendritic (TiN-interdendritic) and dendrite-center (TiN-Dendrite-Center) regions. The influence of $[\mathrm{O}]$ and [S] on the interfacial energy $\sigma$ and, hence, on the nucleation rate $I^{[42]}$ has not been considered here.

Nearly complete homogenization of $\mathrm{C}$ and $\mathrm{N}$ and incomplete homogenization of $\mathrm{Ti}$ and $\mathrm{Nb}$ during slab cooling (Figure 11) may reduce the local difference in $\eta$ values between the interdendritic (TiN-Int. Den.-Homogesd.) and the dendrite center (TiN-Den. Cen.Homogesd.) regions, as shown by the red line in Figure 14(a). The effect of solid-state homogenization on the precipitation has not been considered in the existing precipitation models. ${ }^{[32-34,37-43]}$ Using the predicted $\eta$ values, the critical nucleus size $\left(r^{*}\right)$ for $\mathrm{TiN}$ precipitation has been calculated (Figure 14(b)). 


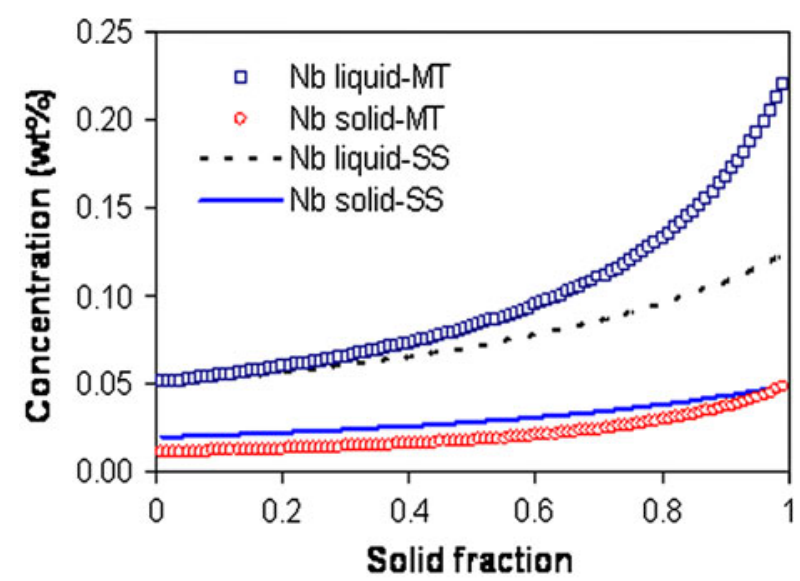

(a)

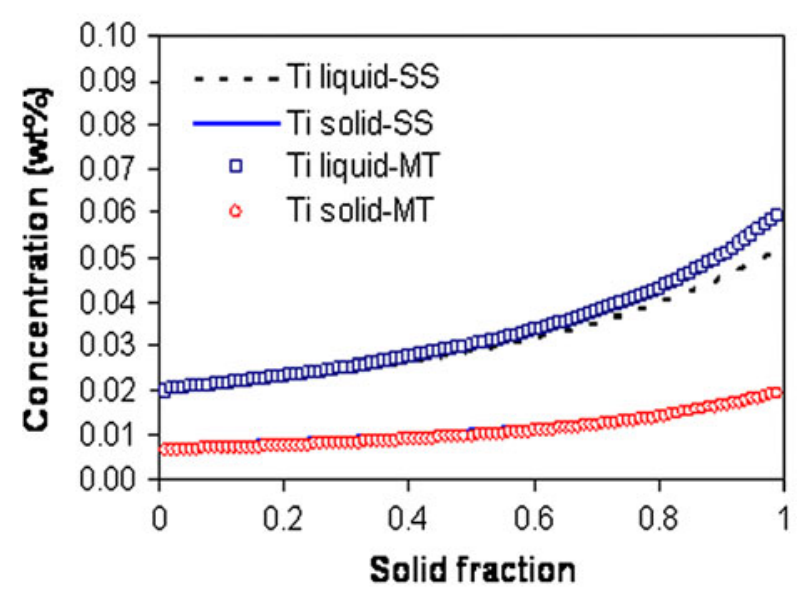

(b)

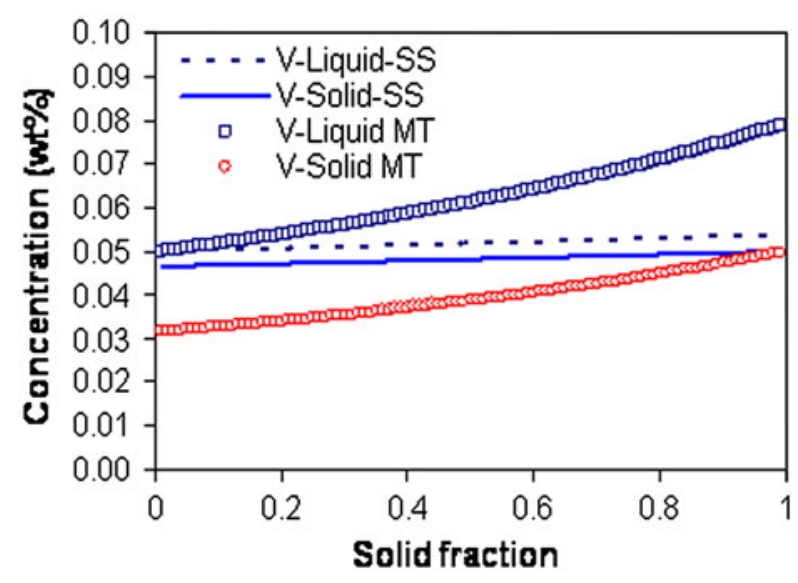

(c)

Fig. 10 - Change in concentration of $(a) \mathrm{Nb},(b) \mathrm{Ti}$, and $(c) \mathrm{V}$, predicted by the Clyne and Kurz model ${ }^{[23]}$ in liquid steel and in solid dendrite at the SS (20-mm below top surface) and near the MT ( $900 \mathrm{~mm}$ below top surface) locations of Slab 1 .

According to the literature, ${ }^{[2,34]}$ the homogeneous nucleation of microalloy precipitates requires $r^{*} \leq 1 \mathrm{~nm}$. The TiN precipitation start temperatures obtained from $r^{*}$ measurement $\left(\sim 1770 \mathrm{~K}\left[\sim 1497^{\circ} \mathrm{C}\right]\right.$ in the interdendritic region and $\sim 1720 \mathrm{~K}\left[\sim 1447{ }^{\circ} \mathrm{C}\right]$ in the dendrite center regions), therefore, closely match those obtained from the Thermo-Calc prediction (Figure 12(a)). A minimum separation of $\sim 2$ to $4 \mu \mathrm{m}$ between the consecutive precipitates in precipitate "rows" (Figure 3(a), $(\mathrm{Nb}, \mathrm{Ti})(\mathrm{C}, \mathrm{N})$ precipitates and Figure 6(a), TiN particles) can be explained by the diffusion field surrounding a particular nucleus, ${ }^{[32,39]}$ which reduces the supersaturation and does not allow another nucleation within that field. As the temperature dropped in the $\gamma$-phase field, $\eta$ reached a high value $(>100)$, resulting in nearly homogeneous distribution of the fine TiN particles throughout the microstructure.

Similar calculations have been carried out for the solid-state precipitation (in $\gamma$ ) of $\mathrm{NbC}$ and VC in Slab 1. The solubility products of microalloy precipitates (Table VI) and their precipitation kinetics during continuous cooling (without deformation) have been collected from published work. ${ }^{[34-36]}$ Heterogeneous precipitation on dislocations, ${ }^{[39]}$ which may generate during the bending and straightening operation, however, not been considered here.

\section{Growth of microalloy precipitates}

Diffusion-controlled growth of a single (spherical) particle of radius $r$, over isothermal holding time $t$ can be obtained from the following equation ${ }^{[43]}$ :

$$
\frac{d r}{d t}=\frac{D_{s}}{r \alpha}\left(\frac{X_{0}-X_{I}}{X_{p}-X_{I}}\right)
$$

where $D_{\mathrm{s}}$ is the diffusion coefficient of the slowest diffusing solute (such as $\mathrm{Nb}$ and $\mathrm{Ti}$ ), $\alpha$ is the ratio of matrix to precipitate atomic volumes, $X_{0}$ is the initial concentration (mole fraction) of the solute (i.e., microalloying elements), and $X_{p}$ is the concentration of solute in the precipitate. $X_{\mathrm{I}}$ is the concentration of solute in the matrix at the particle-matrix interface, which can be obtained from the equilibrium concentration of solute $\left(X_{e}\right)$ in the matrix following the Gibbs-Thomson equation. ${ }^{[44]}$ The concentration of microalloying elements at interdendritic and dendrite center regions predicted by Thermo-Calc $R$ have been considered as the initial concentration $X_{0}$ at those regions (Table V). $X_{p}$ and $X_{e}$ at any temperature below the precipitate dissolution temperature can be obtained from Thermo-Calc. Following the Additivity rule ${ }^{[33]}$ Eq. [12] can be used in a continuous-cooling condition, considering the average cooling rate of the slab (at any location). Hence, it is possible to predict the precipitate growth rate and the final precipitate size at different regions of the investigated slabs. The evolution of precipitate size predicted from the proposed model with respect to the precipitation temperature in the interdendritic and in dendrite center regions of the investigated slabs is shown in Figure 15. The precipitates that nucleate at higher temperatures are expected to grow larger in size (Figure 15), as more time is available for diffusional growth and the diffusion is faster at a higher temperature. The temperature scale along the abscissa in Figure 15 can also be represented as the time from the onset of precipitation, considering the average cooling 
Table V. Concentration of Alloying Elements in Interdendritic and Dendrite Center Regions at QT Location of Slabs 1 and 2 Predicted by Clyne and Kurz Model ${ }^{[23]}$ at the End of Solidification*

Predicted from Clyne-Kurz model ${ }^{[31]}$ for QT location of Slab 1

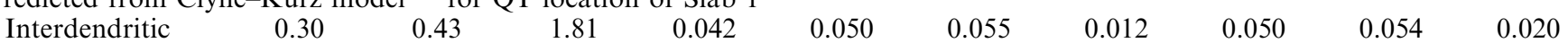

Predicted from Clyne-Kurz model ${ }^{[31]}$ for QT location of Slab 2

\begin{tabular}{llllllllll} 
Interdendritic & 0.350 & 0.233 & 1.55 & 0.051 & 0.080 & 0.05 & -0.100 & - & 0.023 \\
\hline & 0.014 & 0.140 & 0.94 & 0.003 & 0.001 & 0.02 & 0.016 & -0.002
\end{tabular}

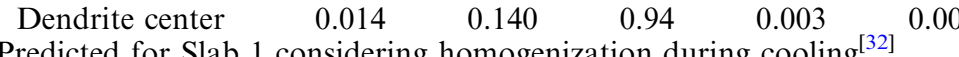

$\begin{array}{llllllllllll}\text { Interdendritic } & 0.090 & 0.38 & 1.64 & 0.025 & 0.020 & 0.040 & 0.090 & 0.040 & 0.050 & 0.007\end{array}$

$\begin{array}{llllllllllll}\text { Dendrite center } & 0.090 & 0.30 & 1.20 & 0.007 & 0.002 & 0.030 & 0.033 & 0.010 & 0.050 & 0.007\end{array}$

Predicted for Slab 2 considering homogenization during cooling ${ }^{[32]}$
Interdendritic
0.07
0.20
1.38
$0.020 \quad 0.030$
$0.04 \quad-\quad 0.070$
$-\quad 0.007$
Dendrite Center
0.16
1.12
$\begin{array}{ll}0.007 & 0.002\end{array}$
0.04
0.023
0.007

${ }^{*}$ Concentrations have also been predicted at those regions, considering the homogenization ${ }^{[24]}$ of as-cast slabs during cooling down to the ambient temperature.

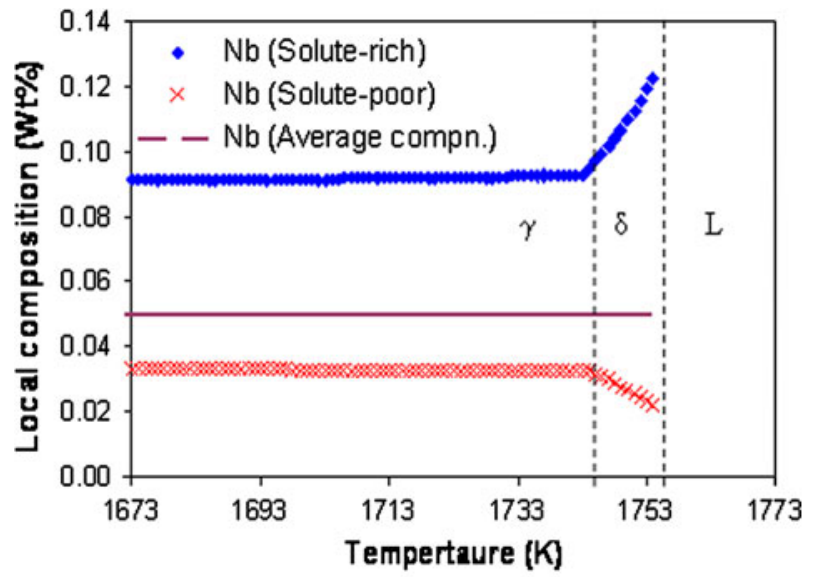

(a)

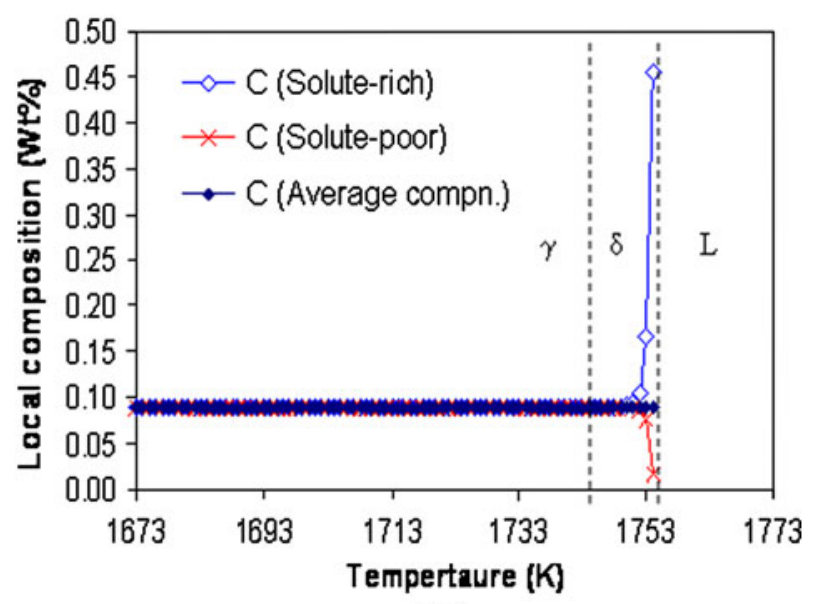

(b)

Fig. 11-Change in concentrations as predicted from Ref. 24 at interdendritic and dendrite center regions in the QT location of Slab 1, showing (a) incomplete homogenization of $\mathrm{Nb}$ and (b) almost complete homogenization of $\mathrm{C}$ during cooling of the as-cast slab.

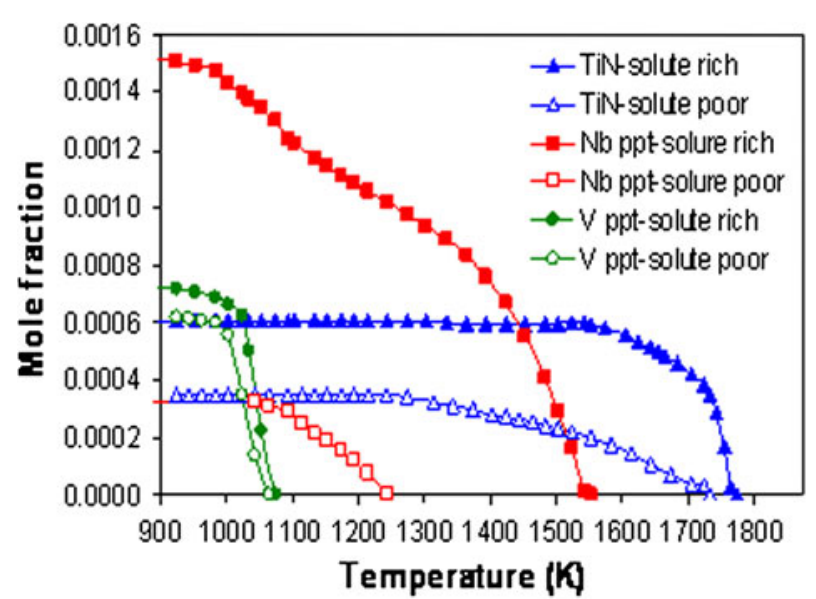

(a)

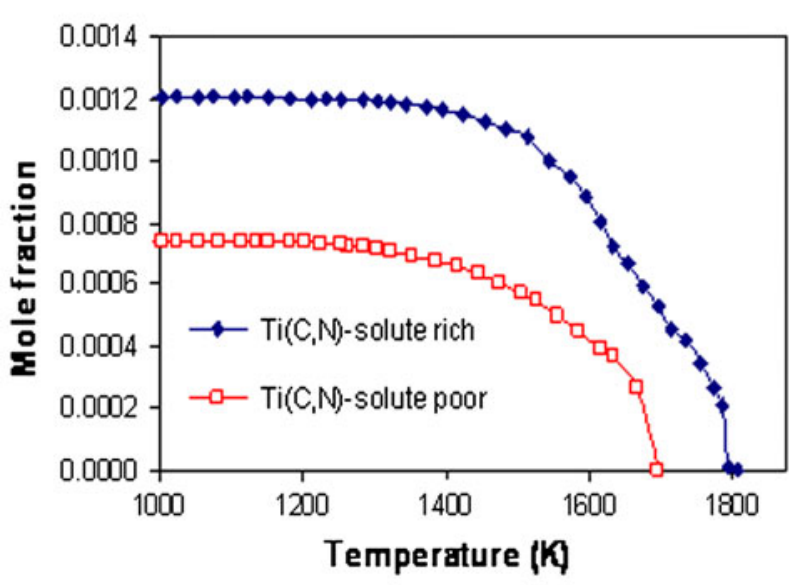

(b)

Fig. 12-Mole fraction and stability of microalloy precipitates in solute-rich and solute-poor (i.e. solute-depleted) regions of (a) Slab 1 and (b) Slab 2, as predicted by Thermo-Calc software. 
Table VI. Structural Details and Solubility Products of Several Precipitates (and Solid-Phases) Observed in the Investigated Steels*

\begin{tabular}{|c|c|c|c|c|}
\hline $\begin{array}{l}\text { Precipitate } \\
\text { (crystal structure) }\end{array}$ & $\begin{array}{c}\text { Lattice } \\
\text { Parameter (nm) }\end{array}$ & $\begin{array}{l}\text { Density } \\
\left(\mathrm{gm} / \mathrm{cm}^{3}\right)\end{array}$ & $\begin{array}{l}\text { Molar Volume } \\
\left(\mathrm{cm}^{3} / \mathrm{mol}\right)\end{array}$ & $\begin{array}{c}\text { Solubility Product } \\
\log _{10}[\mathrm{M}][\mathrm{X}]=\mathrm{A}-\mathrm{B} / \mathrm{T}^{*}\end{array}$ \\
\hline $\operatorname{TiN}\left(\mathrm{fcc}^{\dagger}\right)$ & 0.4233 & 5.42 & 11.44 & $\begin{array}{l}6.40-17,040 / T(\mathrm{~L}) \\
0.322-8,000 / T(\gamma)\end{array}$ \\
\hline $\mathrm{TiC}$ (fcc) & 0.4313 & 4.89 & 12.27 & $\begin{array}{l}2.75-7,000 / T(\gamma) \\
4.4-9,575 / T(\alpha)\end{array}$ \\
\hline $\mathrm{NbN}$ (fcc) & 0.4387 & 8.41 & 12.72 & $4.04-10,230 / T(\gamma)$ \\
\hline $\mathrm{NbC}$ (fcc) & 0.4462 & 7.84 & 13.39 & $\begin{array}{l}2.96-7,510 / T(\gamma) \\
5.43-10,960 / T(\alpha)\end{array}$ \\
\hline $\mathrm{Nb}(\mathrm{C}, \mathrm{N})(\mathrm{fcc})$ & 0.4445 & 8.10 & 12.80 & $\begin{array}{l}\log [\mathrm{Nb}+12 / 14 \mathrm{~N}]= \\
2.06-6,700 / T(\gamma)\end{array}=$ \\
\hline VN (fcc) & 0.4118 & 6.18 & 10.52 & $3.02-7,840 / T(\gamma)$ \\
\hline VC (fcc) & 0.4154 & 5.83 & 10.81 & $\begin{array}{l}6.72-9,500 / T(\gamma) \\
8.05-12,265 / T(\alpha)\end{array}$ \\
\hline $\begin{array}{l}\text { Solid phases } \\
\gamma-\mathrm{Fe}(\mathrm{fcc}) \\
\alpha-\mathrm{Fe}\left(\mathrm{bcc}^{\ddagger}\right)\end{array}$ & $\begin{array}{l}0.357 \\
0.286\end{array}$ & $\begin{array}{l}8.15 \\
7.85\end{array}$ & $\begin{array}{l}6.85 \\
7.11\end{array}$ & \\
\hline
\end{tabular}

$* \mathrm{M}=$ microalloying elements $(\mathrm{Nb} / \mathrm{Ti} / \mathrm{V}) ; \mathrm{X}=$ interstitial solutes $(\mathrm{C} / \mathrm{N}) .^{[1,6,34-36]}$

${ }^{\dagger} \mathrm{fcc}=$ face-centered cubic.

${ }^{\ddagger}$ bcc $=$ base-centered cubic.

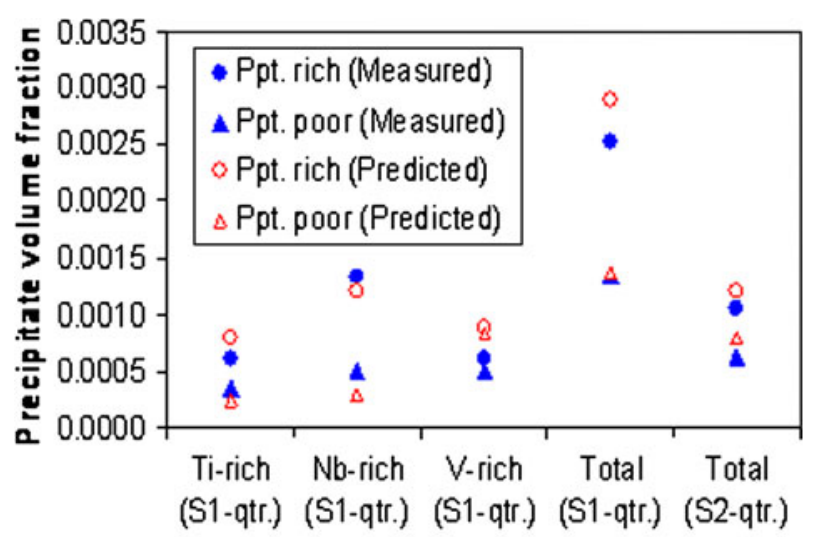

Nature \& Location of Precipitates

Fig. 13-A comparison between the experimentally measured (by image analysis) and the Thermo-Calc-predicted volume fractions of microalloy precipitates at precipitate-rich (ppt. rich) and precipitatepoor (ppt. poor) regions in QR location of Slab 1 (S1-qtr.) and Slab 2 (S2-qtr.).

rate of the slabs. Compared with the dendrite center, larger precipitates should always form in interdendritc regions, where the precipitation starts at a higher temperature. Among the microalloy precipitates, TiN is expected to be largest in size, and the maximum $\mathrm{TiN}$ particle size predicted to form in interdendritic regions of Slab $1(\sim 1.2 \mu \mathrm{m})$ and Slab $2(\sim 8.0 \mu \mathrm{m}$, Figure 15$)$ are close to the experimentally measured values (Figure 8 ). Rapid growth of TiN particles above $1753 \mathrm{~K}\left(1480{ }^{\circ} \mathrm{C}\right)$ (i.e. before the formation of $\gamma$, Figure 15) can be attributed to the higher diffusivity of Ti and $\mathrm{N}$ in liquid steel and in $\delta$ ferrite. As the diffusivity drops with the decrease in temperature, the precipitates formed at lower temperatures, such as VC in Slab 1 and TiC in Slab 2, could only reach a maximum size of 10 to $20 \mathrm{~nm}$ (Figure 15). At precipitation temperatures above

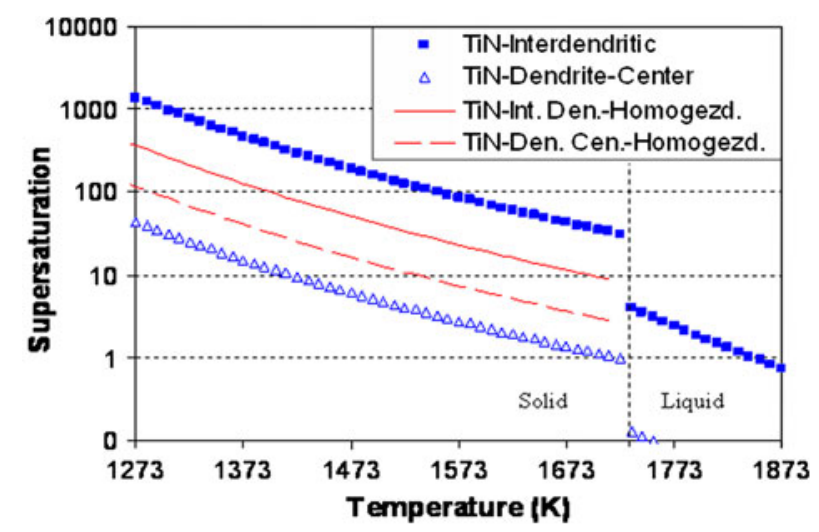

(a)

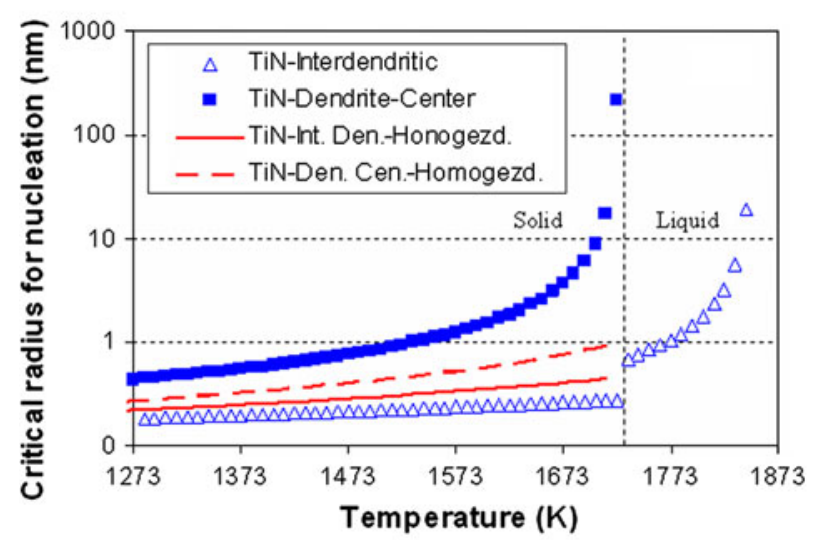

(b)

Fig. 14 (a) A continuous increase in supersaturation $(\eta)$ and the corresponding $(b)$ decrease in the critical nucleus size $\left(r^{*}\right)$ for TiN precipitation in interdendritic and dendrite center regions of Slab 1 during the solidification and subsequent cooling of the slab. Blue symbols indicate $\eta$ and $r^{*}$ values, predicted without considering any solid-state homogenization. Red lines are obtained after considering solid-state homogenization (especially in $\delta$ ferrite) during slab cooling (Color figure online). 


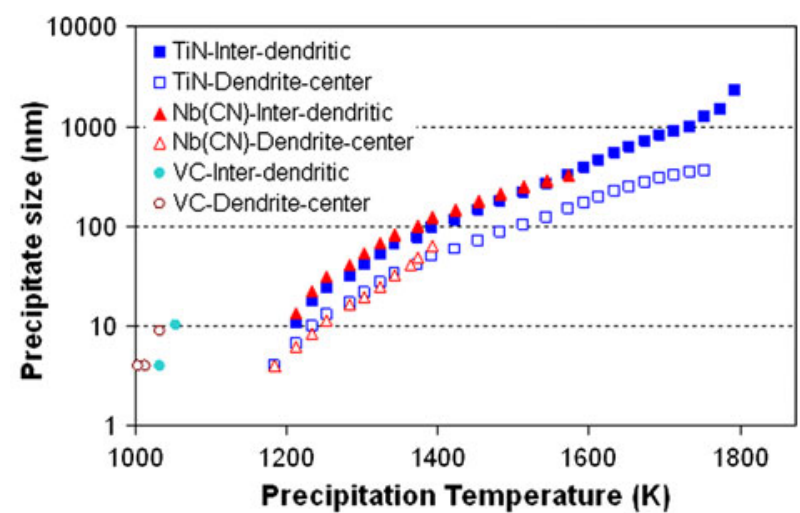

(a)

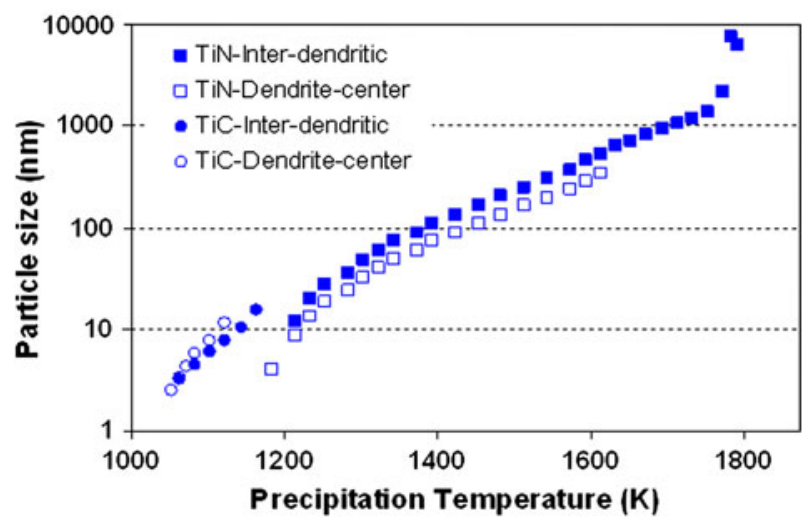

(b)

Fig. 15-The evolution of precipitate size with respect to the precipitation temperature in interdendritic and dendrite center regions of (a) Slab 1 and (b) Slab 2, as predicted by the present model.

$1700 \mathrm{~K}\left(1427^{\circ} \mathrm{C}\right)$, the difference in TiN particle sizes formed in interdendritic and dendrite center regions is more than $500 \mathrm{~nm}$, which drops below $20 \mathrm{~nm}$ at $1400 \mathrm{~K}$ $\left(1127^{\circ} \mathrm{C}\right)$ (Figure 15(a)). This behavior demonstrates the effect of solid-state homogenization on the evolution of precipitate size in a dendritic structure. $\mathrm{Nb}(\mathrm{C}, \mathrm{N})$ precipitates in Slab 1 are predicted to reach a size of $\sim 350 \mathrm{~nm}$, which is slightly lower than the measured value $(600 \mathrm{~nm})$. This finding could be a result of the complex $(\mathrm{Nb}, \mathrm{Ti})(\mathrm{C}, \mathrm{N})$ precipitation or heterogeneous nucleation of $\mathrm{Nb}(\mathrm{C}, \mathrm{N})$ on top of preexisting TiN, which have not been considered in this model.

3. Prediction on the effect of microsegregation on precipitate size distribution

Combining the nucleation rate and growth rate of the precipitates, the size distribution of the precipitates have been determined for solute-rich (i.e., interdendritic) regions and solute-depleted (i.e., dendrite center) regions at the QT location of as-cast slabs (Figure 16). Higher density and larger sizes of $\mathrm{TiN}$ and $\mathrm{Nb}(\mathrm{C}, \mathrm{N})$ precipitates in the solute-rich regions of the slabs are evident from Figure 16. The predicted distributions closely followed the experimentally measured values.

The TiN particles are expected to be the largest of all the microalloy precipitates. A maximum predicted $\mathrm{TiN}$

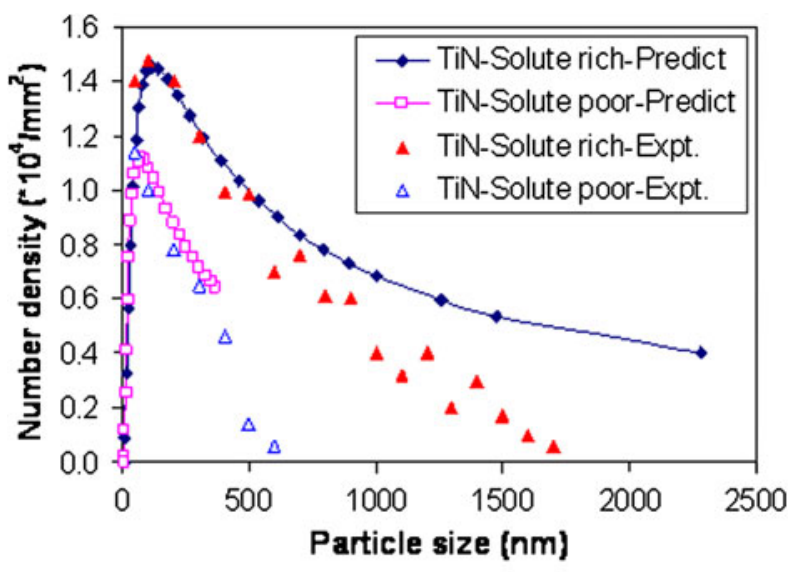

(a)

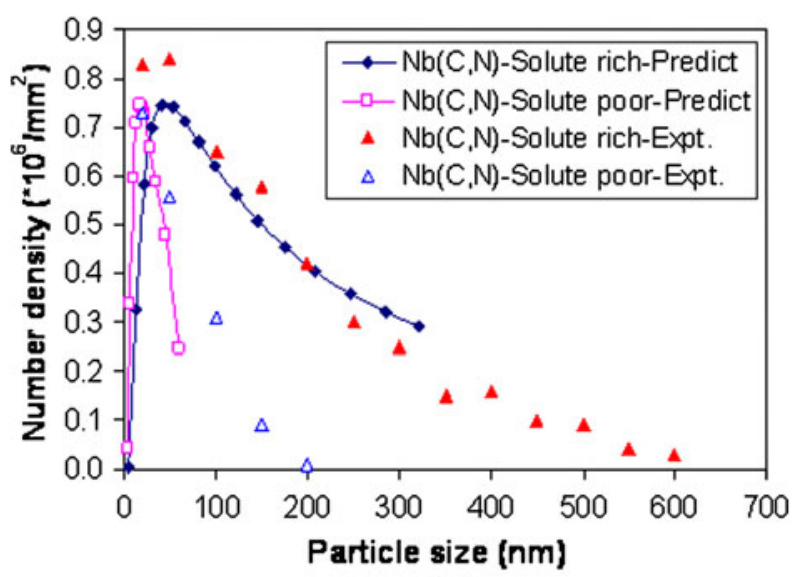

(b)

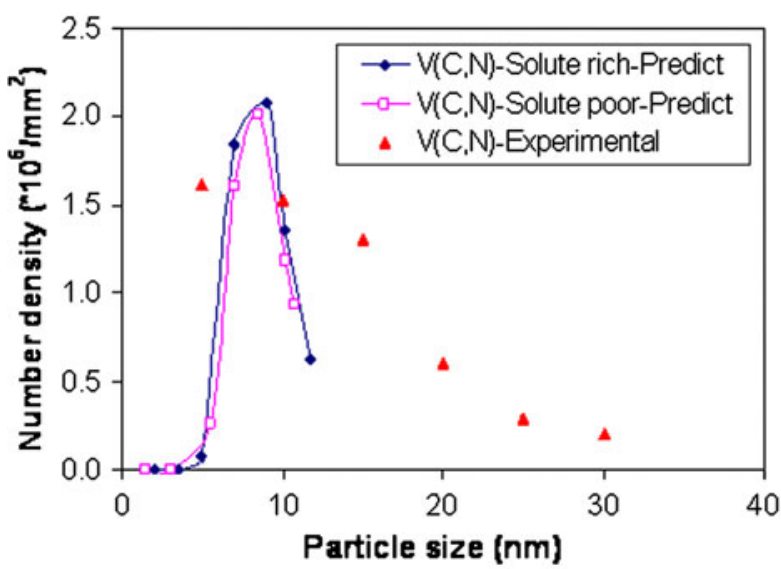

(c)

Fig. 16-A comparison between the predicted size distributions and the measured (experimental) size distributions of $(a)$ TiN, $(b)$ $\mathrm{Nb}(\mathrm{C}, \mathrm{N})$, and $(c) \mathrm{V}(\mathrm{C}, \mathrm{N})$ precipitates in solute-rich and solute-poor regions at the QT location of Slab 1 . V precipitates were uniformly distributed and, hence, could not be distinguished between soluterich and solute-poor regions.

particle size of $\sim 1.6 \mu \mathrm{m}$ in Slab 1 (Figure 16(a)) and of $\sim 8 \mu \mathrm{m}$ in Slab 2 are close to the experimentally measured values. The maximum size of $\mathrm{Nb}(\mathrm{C}, \mathrm{N})$ is 
predicted to be $\sim 600 \mathrm{~nm}$ in Slab 1 (Figure 16(b)), which is smaller than the measured value $(\sim 1.5 \mu \mathrm{m})$. Heterogeneous precipitation of $\mathrm{NbC}$ on top of preexisting $\mathrm{TiN}$ may be the cause of the deviation. Precipitates that formed at lower temperatures, such as VC in Slab 1 and $\mathrm{Ti}(\mathrm{C}, \mathrm{N})$ in Slab 2, could only reach a maximum size of 10 to $20 \mathrm{~nm}$ (Figure 16(c)) as verified by the TEM study.

Continued improvement of the prediction requires the consideration of factors such as stereological correction factors in precipitate quantification, precipitation kinetics of complex precipitates, the effect of segregation of $[\mathrm{S}]$ and $[\mathrm{O}]$ on microalloy precipitation, actual cooling curves of the slabs, and the solidification mode at different locations of the slab. In this context, it is necessary to mention that the partition coefficients $\left(k_{p}\right)$ and diffusivity $\left(D_{\mathrm{s}}\right)$ of any individual alloying element $(e . g ., i)$ as used in the present calculations (Table IV) are valid for a binary solution of element $(i)$ and $\mathrm{Fe}$. Similarly, a binary microsegregation model proposed by Clyne and Kurz ${ }^{[23]}$ has been used here for the backdiffusion calculation to predict the segregation level of individual alloying elements. However, in multicomponent systems, as the investigated steels, the presence of other solute elements (e.g., $j, k$, and $l$ ) can influence the partitioning and diffusion of element $(i)$. To avoid complex mathematical calculations, these interaction effects have not been considered here, although it may introduce a certain error in the final prediction. Future studies need to consider this aspect for more accurate prediction.

To understand the sensitivity of the prediction on the choice of microsegregation models, the maximum precipitate sizes in Slab 1 have been predicted separately, considering the Scheil equation, Clyne and Kurz ${ }^{[23]}$ back-diffusion model, and Lever rule. Figure 17 shows the different $\mathrm{Nb}$ levels predicted by these models in the interdendritic liquid of Slab 1, with the increase in solid fraction. Compared with the other models, the Scheil model predicts a significantly higher $\mathrm{Nb}$ level in the last solidifying liquid $(0.79 \mathrm{wt} \mathrm{pct})$, which is predicted to form $\mathrm{Nb}(\mathrm{C}, \mathrm{N})$ precipitates as large as $5 \mu \mathrm{m}$ in liquid

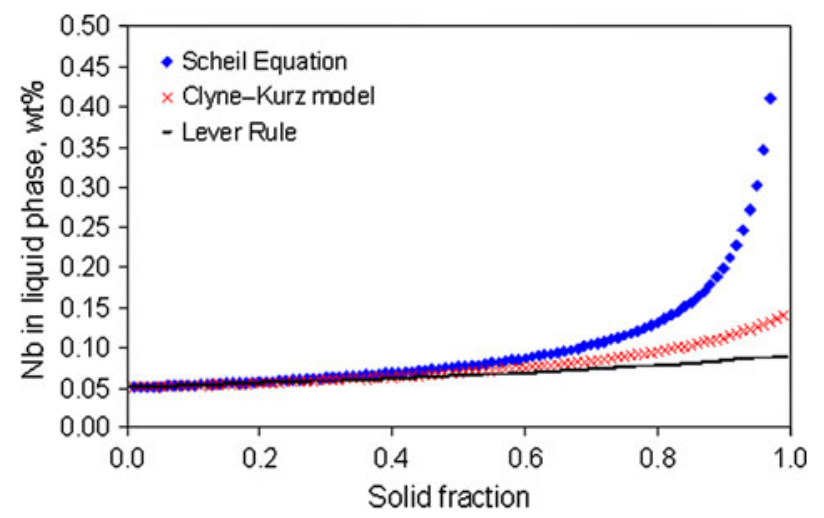

Fig. 17-A comparison of $[\mathrm{Nb}]$ concentration in interdendritic liquid, with respect to the solid fraction, calculated from the different microsegregation models. steel. The largest $\mathrm{Nb}(\mathrm{C}, \mathrm{N})$ precipitate size measured from the experimental study $(600 \mathrm{~nm})$ is far less than the predicted value. Similarly, the maximum TiN particle size predicted in interdendritic liquid $(25 \mu \mathrm{m})$ considering the Scheil model is much higher than the measured size $(1.8 \mu \mathrm{m})$. The Scheil model, therefore, seriously overpredicts the extent of microsegregation (Table III) and the corresponding precipitate size in the interdendritic regions. The microsegregation levels predicted by the Clyne and Kurz model is between the Scheil model and the Lever rule, and the satisfactory prediction of precipitate sizes from the Clyne and Kurz model is evident in Figure 16. The maximum precipitate sizes predicted in Slab 1 from the Level rule $(260 \mu \mathrm{m}$ for $\mathrm{Nb}(\mathrm{C}, \mathrm{N})$ and $960 \mu \mathrm{m}$ for $\mathrm{TiN})$ were not as good as the Clyne and Kurz model, but were certainly better than that of the Scheil model. The prediction of precipitate size, therefore, was dependent on the microsegregation model. The present findings are in line with the observations of Won and Thomas ${ }^{[31]}$ and Choudhary and Ghosh ${ }^{[29]}$ regarding the prediction of microsegregation in low-carbon steels, although, future study will compare different models is greater detail.

\section{SUMMARY AND CONCLUDING REMARKS}

Spatial distribution in size and frequency of microalloy precipitates have been characterized using high-resolution SEM and TEM in two continuous-cast HSLA steel slabs, one containing $\mathrm{Nb}, \mathrm{Ti}$, and $\mathrm{V}$ and the other containing only $\mathrm{Ti}$. Microsegregation during casting resulted in an inhomogeneous distribution of $\mathrm{Nb}$ and $\mathrm{Ti}$ precipitates in as-cast slabs, and precipitate-rich regions were separated by a distance similar to the SDAS. Large networks (several microns in size) of $\mathrm{Nb}$ - and Ti-rich phases were found at the segregated regions in the MT location, indicating the strong microalloy segregation during solidification. Such segregation can reduce the effective microalloy level of the steel required for finescale precipitation during and after rolling for grain refinement and precipitation strengthening.

Considering the microsegregation during solidification, the homogenization of the alloying elements during slab cooling, the thermodynamics of precipitation (using Thermo-Calc software), and the kinetics of precipitation (calculating the nucleation and growth-rate of precipitates), a model has been proposed here for predicting the precipitate size distribution and the amount of precipitates in the interdendritic and dendrite center regions in the segregated slabs. A comparison of the predicted results and the experimental data for precipitate characterization showed satisfactory prediction.

The accurate prediction and control over the precipitate size and fractions may help (1) in avoiding the hotcracking problem and, hence, improve the slab quality, (2) in selecting the soaking time and temperature and predicting the $\gamma$ grain size during soaking, and (3) in designing the rolling schedule for achieving the maximum benefit from the microalloy precipitates. 


\section{ACKNOWLEDGMENTS}

The authors would like to thank the Indian Institute of Technology Kharagpur for the provision of the ISIRD project research grant and the research facilities at the Department of Metallurgical and Materials Engineering Department, Steel Technology Centre and Central Research Facility. They would also like to acknowledge the help provided by Mr. Sukata Mandal in the characterization using SEM and Tata Steel, Jamshedpur for the provided research materials. The authors would also like to sincerely thank Dr. G.K. Dey and Dr. D. Srivastava from the Materials Science Division of Bhabha Atomic Research Centre, Mumbai for their constant support and encouragement in this work.

\section{REFERENCES}

1. T. Gladman: The Physical Metallurgy of Microalloyed Steels, Book 615, The Institute of Materials, London, UK, 1997, p. 80.

2. B. Dutta, E. Valdes, and C.M. Sellars: Acta Metall. Mater., 1992, vol. 40 , pp. $653-62$.

3. T. Gladman: Proc. of Royal Society of London, 1966, vol. 294, pp. 298-309.

4. D. Chakrabarti, C.L. Davis, and M. Strangwood: Metall. Mater. Trans. A, 2008, vol. 39A, pp. 1963-77.

5. L.P. Zhang, C.L. Davis, and M. Strangwood: Proc. Conf. on 'Thermomechanical Processing of Steels, IoM Communications, London, UK, 2000, pp. 764-75.

6. H.J. Jun, K.B. Kang, and C.G. Park: Scripta Mater., 2003, vol. 49, pp. 1081-86.

7. A.G. Kneissi, C.I. Garcia, and A.J. DeArdo: Proc. 2nd Int. Conf. on HSLA Steels: Processing, Properties and Applications, G. Tither and Z. Shouhua, eds., TMS, Warrendale, PA, 1992, pp. 99-105.

8. H. Kejian and T.N. Baker: Proc. of Conf. on Titanium Technology in Microalloyed Steels, T.N. Baker, ed., Book 662, The Institute of Materials, London, UK, 1997, pp. 115-32.

9. B. Mintz and D.N. Crowther: Proc. of Conf. on Titanium Technology in Microalloyed Steels, T.N. Baker, ed., Book 662, The Institute of Materials, London, UK, 1997, pp. 98-114.

10. D.W. Tian, L.P. Karjalianen, B. Qian, and X. Chen: Metall. Mater. Trans. A, 1996, vol. 27A, pp. 4031-38.

11. P.H. Li, A.K. Ibraheem, and R. Priestner: Mater. Sci. Forum, 1998, vols. 284-286, pp. 517-524.

12. M.J. Leap and E.L. Brown: Scripta Mater., 2002, vol. 47, pp. 793 7.

13. A.J. Craven, K. He, L.A.J. Garvie, and T.N. Baker: Acta Mater., 2000, vol. 48, pp. 3857-68.
14. A.J. Craven, K. He, L.A.J. Garvie, and T.N. Baker: Acta Mater., 2000, vol. 48, pp. 3869-78.

15. M.T. Nagata, J.G. Speer, and D.K. Matlock: Metall. Mater. Trans. A, 2002, vol. 33A, pp. 3099-110.

16. A. Ruiz-Aparicio: Master's Thesis, University of Pittsburgh, Pittsburgh, PA, 2004.

17. C. Zhou and R. Priestner: ISIJ Int., 1996, vol. 36, pp. 1397-1405.

18. C.L. Davis and M. Strangwood: J. Mater. Sci., 2002, vol. 37, pp. 1083-90.

19. R. Varano, A.M. Elwazri, F. Siciliano, D. Bain, R. Gawin, and S. Yue: Mater. Sci. Forum, 2005, vols. 500-501, pp. 663-68.

20. A.J. Couch: Ph.D. Dissertation, University of Leeds, UK, 2001.

21. M. Puder, S. Zamberger, K. Spiradek-Hahn, and E. Kozeschnik: Steel Res. Int., 2010, vol. 81, pp. 372-80.

22. G.A. de Toledo, A. Arteaga, and J.J. Larau Dogoita: Mater Sci. Forum, 2005, vols. 500-501, pp. 163-70.

23. T.W. Clyne and W. Kurz: Metall. Trans. A, 1981, vol. 12A, pp. $965-71$.

24. W. Kurz and D.J. Fisher: Fundamentals of Solidification, Trans. Tech. Publications, Aedermannsdorf, Switzerland and Germany, 1989, p. 290.

25. M. El-Bealy and B.G. Thomas: Metall. Mater. Trans. B, 1996, vol. 27B, pp. 689-93.

26. E. Scheil: Z. Metallkd., 1942, vol. 34, pp. 70-72.

27. A. Ghosh: Sadhana, 2001, vol. 26, pp. 5-24.

28. G. Krauss: Metall. Mater. Trans. B, 2003, vol. 34B, pp. 781-92.

29. S.K. Choudhary and A. Ghosh: ISIJ Int., 2009, vol. 49, pp. 1819 27.

30. H.D. Brody and M.C. Flemings: Trans. TMS-AIME, 1966, vol. 236, pp. 615-24.

31. Y.M. Won and B.G. Thomas: Metall. Mater. Trans A, 2001, vol. $32 \mathrm{~A}$, pp. $1755-67$.

32. J. Kunze, C. Mickel, M. Leonhardt, and S. Oswald: Mater. Tech. Steel Res., 1997, vol. 68, pp. 403-08.

33. E. Scheil: Arch. Eisenhüttenwes, 1935, vol. 12, pp. 565-67.

34. S. Okaguchi and T. Hashimoto: ISIJ Int., 1992, vol. 32, pp. 28390.

35. B. Dutta, E.J. Palmiere, and C.M. Sellars: Acta Mater., 2001, vol. 49, pp. 785-94.

36. P. Maugis and M. Goune: Acta Mater., 2005, vol. 53, pp. 3359-67.

37. Z. Ma and D. Janke: ISIJ Int., 1998, vol. 38, pp. 46-52.

38. Y. Kawashita and H. Suito: ISIJ Int., 1995, vol. 35 (12), pp. 146876.

39. J. Kunze, C. Mickel, G. Backmann, B. Beyer, M. Reibold, and C. Klinkenberg: Steel Res., 1997, vol. 68, pp. 441-49.

40. P. Rocabois, J. Lehmann, H. Gaye, and M. Wintz: J. Cryst Growth, 1999, vols. 198-199, pp. 838-43.

41. J.W. Christian: The Theory of Transformations in Metals and Alloys, 2nd ed., Pergamon Press, New York, NY, 1975, pp. 432-48.

42. J.D. Robson: Mater. Sci. Tech., 2004, vol. 20, pp. 441-48.

43. M. Perez, M. Dumont, and D. Acevedo-Reyes: Acta Mater., 2008, vol. 56 , pp. 2119-32.

44. M. Perez: Scripta Mater., 2005, vol. 52, pp. 709-12. 